Fayetteville State University

DigitalCommons@Fayetteville State University

Math and Computer Science Faculty Working

Papers

Math and Computer Science

$3-2014$

\title{
Theoretical Analysis and Simulation of Acute and Chronic Phase HIV-1 Dynamics
}

Frank Nani

Fayetteville State University, fnani@uncfsu.edu

Mingxian Jin

Fayetteville State University, mjin@uncfsu.edu

Follow this and additional works at: https://digitalcommons.uncfsu.edu/macsc_wp

Part of the Computer Sciences Commons, Diseases Commons, Life Sciences Commons, and the Mathematics Commons

\section{Recommended Citation}

Nani, Frank and Jin, Mingxian (2014). "Theoretical Analysis and Simulation of Acute and Chronic Phase HIV-1 Dynamics", British Journal of Mathematics \& Computer Science 4(11): 1450-1479, 2014. Print

This Article is brought to you for free and open access by the Math and Computer Science at DigitalCommons@Fayetteville State University. It has been accepted for inclusion in Math and Computer Science Faculty Working Papers by an authorized administrator of DigitalCommons@Fayetteville State University. For more information, please contact dballar5@uncfsu.edu. 


\title{
Theoretical Analysis and Simulation of Acute and Chronic Phase HIV-1 Dynamics
}

\author{
Frank Nani ${ }^{1 *}$ and Mingxian Jin ${ }^{1}$ \\ ${ }^{1}$ Department of Mathematics and Computer Science, Fayetteville State University 1200 \\ Murchison Road Fayetteville, North Carolina 2830, USA.
}

\begin{abstract}
Aims: The dynamics of HIV-1 induced AIDS is attributed to several biological variables, which characterize the stage, virulence and morbidity of the disease. The aim of this research is to use a necessary and sufficient subset of these immunological variables to construct a clinically plausible mathematical model of the patho-physiological dynamics of HIV-1 induced AIDS during the acute and chronic phases. This model incorporates the interactions between uninfected CD4+ T cells, HIV-1 infected CD4+ T cells, HIV-1 virions in the blood plasma, and specific cytotoxic $\mathrm{CD} 8+\mathrm{T}$ cells. The major objective is to derive mathematical criteria depicting conditions under which the HIV-1 virions can be maintained definitely at the subclinical viral blood plasma level such that the HIV-1 seropositive person does not develop full-blown AIDS.

Study Design: The model is based on contemporary published patho-physiological data on acute and clinical chronic phase HIV-1 induced AIDS. These data are meticulously condensed into a clinically plausible four-compartmental mathematical model that incorporates the dynamics and interactions between non-HIV-1 infected CD4+ T lymphocytes. HIV-1 infected lymphocytes, free HIV-1 virions in the blood plasma, and HIV-1 specific cytotoxic CD8+ T lymphocytes. The relevant stoichiometric interaction rate constants, apoptotic rate constants, rate constants for viral recruitment from latent reservoirs, and other relevant parameters are clearly exhibited in the mathematical model. The role of CD4+ T cell-induced syncytia is explicitly incorporated into the HIV-1 virion dynamical equation.

Place and Duration of Study: This research was done at Fayetteville State University, North Carolina USA and is sponsored by the FSU Mini-Grant Award and the HBCU Graduate STEM Grant. The research was conducted during the Spring of 2012.

Methodology: The deterministic nonlinear HIV-1 AIDS patho-physio-dynamical equations are analyzed using the techniques of dynamical system theory, principles of linearized stability, Hartman-Grobman theory and other relevant mathematical techniques. The clinically desirable equilibrium states are and their local existence and global stability are analyzed. Investigative computer simulations are performed illustrating some physiological outcomes.
\end{abstract}

Results: Mathematical criteria are derived under which the clinically desired outcomes can 
occur. These criteria are presented in terms of theorems. Investigative computer simulations are presented which elucidate a number of physiological scenarios of primary HIV-1 infection, involving the annihilation and persistence of HIV -1 in the absence of AIDS Pharmacotherapy.

Conclusion: This research has demonstrated the existence of plausible criteria under which an HIV-1 sero-positive person can be maintained at an asymptomatic chronic state indefinitely. Some of the criteria are configured in terms of clinically measurable and biological quantifiable parameters which have been verified by the computer simulations.

Keywords: HIV-1 annihilation criteria, mathematical model, computer simulations, acute and chronic phase.

\section{Introduction}

Human Immunodeficiency Virus (HIV) belongs to a family of ribonucleic (RNA) lenti-viruses. In particular, the epidemiologically common subtype called HIV-1 is implicated for causing the Human Acquired Immunodeficiency Syndrome (AIDS). The pathogenesis of AIDS can be divided into three main phases called the acute phase, the clinical latency phase and the full-blown AIDS phase.

The HIV-1 virion uses the glycoprotein gp 120 to locate the CD4 surface molecules and the host cells. By means of CCR5 or CXCR4, the HIV-1 virions fuses to the host cell surfaces and eventually enter the cell. The CD4 $+\mathrm{T}$ cells are the major targets for the HIV -1 virions. But macrophages, monocytes, neurons, astrocytes, and microglia cells in the central nervous system (CNS) possess CCR5 chemokine co-receptors and hence are targets of HIV-1 virions. These findings are summarized in [1-3]. The pathogenesis of HIV-1 infection comprises the virus life cycle, the host cellular environment and the viral load in the infected person. There exist strains of HIV-1 virus known as T-tropic and M-tropic which interact respectively with the CXCR4 and CCR5 chemokine co-receptors.

During the acute phase of HIV-1 infection, the person is seropositive after exposure and immunological reaction to the initial viral inoculum. The person experiences transient infection resembling mononucleosis for 1-12 weeks. The symptomatic primary HIV-1 infection is usually characterized by fever, lymphadenopathy, pharyngitis, arthralgia, rash and lethargy. This is called acute retroviral syndrome (ARS) and is experienced by most but not all of the HIV-1 infected persons. During this phase, large amount of HIV-1 virions are produced inside the patient body. Inside the patient body, the HIV-1 viral envelope decoates and HIV RNA, reverse transcriptase, integrase and other viral protein enter the host cell leading to formation of a pre-integration complex inside the host cell such as the CD4+ $\mathrm{T}$ cells. Then reverse transcriptase is used to produce HIV-1 viral DNA. The viral DNA is transported across the nucleus of the host cell and integrates into the host DNA. The next step is the production of new HIV-1 viral proteins using the HIV-1 viral RNA as genomic RNA. HIV proteases cleave newly synthesized polyproteins at the appropriate places to create the mature protein components of an infectious HIV virion. Then the new viral RNA and viral proteins migrate to the host surface and form a new immature HIV 1 provirus. The mature newly formed HIV-1 virions exit the host cell by a process called budding. In particular, several millions of virus RNA copies may be released into the blood plasma of the patient.

After 3 months, the chronic clinical latency phase starts. During this phase, the rate of HIV-1 replication in the host cell decreases as the CD4+ $\mathrm{T}$ cells numbers increases as a result of the 
cytotoxic intervention of the body's immune system mounted by the CD8+ T cells. In particular, it is possible at this stage for the blood plasma HIV-1 viral titre to be subclinical and plunge to undetectable levels. This may continue up to 8 years or longer, according to the results obtained in [4-7].

The third phase of HIV-1 dynamics is characterized by a rapid exponential increase in the number of HIV-1 virions in the blood plasma, increase in the number of HIV-1 infected $\mathrm{CD}_{4}+\mathrm{T}$ cells and a rapid decrease of uninfected CD4 $+\mathrm{T}$ cells to a level below 200 cells per microliter and a complete failure of the anti-HIV cytotoxic activity of CD8+ T cells. The details are found in $[8,9]$.

Several mathematical models of HIV-1 dynamics have been constructed by many authors in [4,10-16]. These authors proposed various mathematical models which describe certain aspects of HIV-1 life cycle with the aim of finding criteria for cure of AIDS or present a quantitative analysis of the dynamics of the HIV-1 virus. Authors in [17] presented a detailed analysis of three different mathematical models with regard to local and global stability of infected and uninfected equilibrium (steady) states of HIV-1 infection. Their analysis also included the dynamics of time delay models. Authors in [18] performed an elaborate analysis of the global dynamics of a mathematical model for HTLV-1 infection of CD4+ T cells with delayed CTL response. In particular, they demonstrated that the time delay can destabilize the system equilibrium leading to Hopf bifurcations and stable periodic oscillations. Similar analysis of the global dynamics of HIV1 infection of CD4+ T cells was done in [19]. They obtained some interesting results on the stability of infected and non-infected equilibrium states of AIDS infection. A stochastic model for HIV-1 population dynamics has been presented and analyzed in [20]. In particular, they analyzed the random fluctuations associated with HIV-1 infection and dynamics. In the forthcoming paper, we will present a stochastic model of HIV-1 dynamics which incorporates viral contributions from latent reservoirs and also accounts for apoptosis. The interactions of the model equations will incorporate mathematical analogues of the physiological processes suggested in the works published in [5,8,21-29].

In this paper, new mathematical models for the acute phase and the asymptomatic clinical latency phase are proposed and analyzed. In particular, elaborate and robust mathematical criteria will be presented elucidating the conditions under which the chronic clinical latency phase can be maintained indefinitely in the seropositive HIV-1 infected person.

\section{Definition and Description of Model Parameters}

The model of HIV-1 patho-physio- dynamics presented in this paper contains many variables and constant parameters. These parameters include stoichiometric interaction coefficients, cellular degradation rate constants, apoptotic rate constants, rate constants for production of immune cells from the thymus gland via haematopoietic progenitors, rate constants for recruitment of HIV-1 virions from latent reservoirs, intra-specific competition rate constants between infected / uninfected CD4 $+\mathrm{T}$ cells, and activation constants for CD4+/CD8+ T cells. The catalogue of constants is presented as follows.

$x_{1}$ : the number density of un-infected $\mathrm{CD} 4^{+}$helper T-lymphocytes per unit volume $x_{2}$ : the number density of HIV-1 infected $\mathrm{CD}^{+}$helper T-lymphocytes per unit volume $x_{3}$ : the number density of HIV-1 virions in the blood plasma per unit volume 
$x_{4}$ : the number density of HIV-1 specific $\mathrm{CD} 8^{+}$cytotoxic T-lymphocytes per unit volume

$S_{1}$ : rate of supply of un-infected antigen exposed $\mathrm{CD}^{+} \mathrm{T}_{4}$-lymphocytes from the Thymus

$S_{2}$ : rate of supply of latently infected $\mathrm{CD}^{+} \mathrm{T}_{4}$-lymphocytes

$S_{3}$ : rate of supply of HIV-1 virions from macrophage, monocytes, microglial cells and other lymphoid tissue different from $\mathrm{T}_{4}$-lymphocytes

$S_{4}$ : rate of supply of $\mathrm{CD}^{+} \mathrm{T}_{8}$-lymphocytes from the Thymus

$a_{i}, b_{i}$ : constant associated with activation of lymphocytes by cytokine interleukin-2 (IL-2) where $i=\{1,2,4\}$

$\alpha_{i}$ : constant associated with HIV-1 infection of $\mathrm{CD}^{+} \mathrm{T}_{4}$ helper cells

$\beta_{1:}$ the number of HIV-1 virions produced per day by replication and budding in $\mathrm{CD}^{+} \mathrm{T}_{4}$ helper cells

$\beta_{2}$ : rate constant associated with replication and "budding" of HIV-1 in syncytia CD4 $4^{+} \mathrm{T}_{4}$ helper cells per day per micro liter $(\mu l)$ and released into the blood plasma

$\beta_{3:}$ the number of HIV-1 virions produced per day by replication and "budding" in nonsyncytia $\mathrm{CD}^{+} \mathrm{T}_{4}$ helper cells and released into the blood plasma

$q_{i}$ : constant depicting competition between infected and un-infected $\mathrm{CD}^{+} \mathrm{T}_{4}$ helper cells

$k_{i}$ : constant depicting degradation, loss of clonogenicity or "death"

$e_{i 0}$ : constant depicting death or degradation or removal by apoptosis (programmed cell death)

$K_{i}$ : constant associated with the killing rate of infected $\mathrm{CD}^{+} \mathrm{T}_{4}$ cells by $\mathrm{CD} 8^{+} \mathrm{T}_{8}$ cytotoxic lymphocytes

\section{Model Description and Analysis}

In this section, the mathematical formulation for the acute and chronic phase of HIV-1 pathophysio-dynamics will be presented. In describing the model, the activation function is given by the expression:

$$
g\left(x_{1}, x_{j}\right)=a_{j} x_{1} x_{j} e^{-b_{j} x_{1}} \quad \text { for } j=\{1,2,4\}
$$

In particular, this function depicts the process of lymphocyte activation which is mediated by $x_{1}$ (CD 4+) helper T cells, where $a_{j}, b_{j}$ are constants associated with activation of lymphocytes by cytokine interleukin-2 (IL-2). These cells secrete a lymphokine called interleukin-2. In the activation process, the $a_{j}$ coefficient is a measure of the duration whereas the $b_{j}$ coefficient modulates the peak of the activation. If $j$ equals to 1 , then the interleukin-2 activation of helper T cells $x_{1}$ which is represented by $g\left(x_{1}, x_{1}\right)$ is an autocrine process; otherwise, the $g\left(x_{1}, x_{j}\right)$ activation function depicts a paracrine process for $j=\{2,4\}$.

\subsection{The Description of the Mathematical Model}

\subsubsection{The CD4+ T cell dynamics}

$$
\dot{x}_{1}=S_{1}+a_{1} x_{1}^{2} e^{-b_{1} x_{1}}-\alpha_{1} x_{1} x_{3}-q_{1} x_{1} x_{2}-k_{1} x_{1}-e_{10}
$$

The instantaneous number of uninfected CD4+ $\mathrm{T}$ cells in the blood plasma of the patient at any time during the acute or chronic phase is equal to the rate of supply of uninfected CD4+ T cells 
from the thymus via hematopoietic progenitor cells $\left(S_{1}\right)$; plus the activation/proliferative recruitment of antigen activated and interleukin-2 stimulated CD4+ T cells $\left(a_{1} x_{1}^{2} e^{-b_{1} x_{1}}\right)$; less the number of CD4+ cells recruited into the pool of HIV-1 infected CD4+ T cells by infection with HIV-1 virions ( $\left.{ }^{\alpha_{1} x_{1} x_{3}}\right)$; less the number of CD4+ T cells lost by intra-specific competition with HIV-1 infected CD4+ T cells $\left(q_{1} x_{1} x_{2}\right)$; less the number of CD4+ $\mathrm{T}$ cell lost by enzymatic degradation $\left({ }_{1} x_{1}\right)$ and less the number of $\mathrm{CD} 4+\mathrm{T}$ cells lost by apoptosis/exfoliative cytolytic death $\left({ }^{e_{10}}\right)$. The existence of the HIV-1 virion recruitment from the reservoirs as depicted by $S_{1}$ explained in [26]. The autocrine activation term of the equation is explained [30]. The apoptotic degradation term of the equation is discussed in [31].

\subsubsection{The HIV-1 infected CD4+ dynamics}

$$
\dot{x}_{2}=S_{2}+a_{2} x_{1} x_{2} e^{-b_{2} x_{1}}+\alpha_{2} x_{1} x_{3}-q_{2} x_{1} x_{2}-k_{2} x_{2}-\beta_{1} x_{3}-K_{1} x_{2} x_{4}-e_{20}
$$

The instantaneous number of HIV-1 infected CD4+ T cells in the blood plasma of the patient during the acute or chronic phase is equal to the rate of supply of HIV infected CD4+ T cells from resting CD4+ T cells $\left(S_{2}\right)$; plus the activation/proliferative recruitment of antigen activated and interleukin-2 stimulated HIV-1 infected CD4+ T cells $\left(a_{2} x_{1} x_{2} e^{-b_{2} x_{1}}\right)$; plus the addition of the HIV-1 infected CD4+ T cells ( $\left.{ }^{\alpha_{2} x_{1} x_{3}}\right)$; less the number of CD4+ T cells lost by intra-specific competition with HIV-1 uninfected CD4+ T cells $\left(q_{2} x_{1} x_{2}\right)$; less the number of HIV-1 infected $\mathrm{CD} 4+\mathrm{T}$ cell lost by enzymatic degradation $\left(k_{2} x_{2}\right)$ and less the number of HIV-1 infected CD4+ T cells lost as a result of budding of newly produced virions $\left(\beta_{1} x_{3}\right)$; less the number of HIV-1 infected CD4+ T cells lost by cytolytic action by HIV-1 specific CD8+ T cells $\left(K_{1} x_{2} x_{4}\right)$ and less the number of HIV-1 infected CD4+ T cells lost by apoptosis/exfoliative cytolytic death $\left({ }^{e_{20}}\right)$. The existence of the reservoirs for latently infected CD4+ T cells as depicted by $S_{2}$ term is explained in [32]. The existence of the term $K_{1} x_{2} x_{4}$ is due to the research data from [8, 23].

\subsubsection{The blood plasma HIV-1 virion dynamics}

$$
\dot{x}_{3}=S_{3}+\beta_{2} x_{2} x_{3}+\beta_{3} x_{3}-\alpha_{3} x_{1} x_{3}-k_{3} x_{3}-e_{30}
$$

The instantaneous number of HIV-1 virions in the blood plasma of the patient is equal to the rate of supply of HIV-1 virions from the latently infected viral reservoirs $\left({ }^{S_{3}}\right)$; plus the number of HIV-1 virions released from the syncytia of CD4+ T cells/dendritic cells/macrophages ( $\left.\beta_{2} x_{2} x_{3}\right)$; plus the number of HIV-1 virions released from budding HIV-1 infected CD4+ T cells ( $\left.\beta_{3} x_{3}\right)$; less the number of HIV-1 virions lost during infection of CD4+ T cells ( $\left.\alpha_{3} x_{1} x_{3}\right)$; less the number of HIV-1 virions lost by enzymatic degradation/catabolism ( $\left.k_{3} x_{3}\right)$ and less the number of HIV-1 virions lost in the form of unintegrated HIV-1 DNA molecules per provirus $\left({ }^{e_{30}}\right)$. Also, the $e_{30}$ 
term includes the HIV-1 infected CD4+ T cells which are no longer in the clone of uni-nucleated CD4+ T cells due to the formation of multi-nucleated syncytia.

The inclusion of the $\left(\beta_{2} x_{2} x_{3}\right)$ and $\left(\beta_{3} x_{3}\right)$ terms account for the two mechanisms for HIV -1 virions production in the CD4+ T cells and dissemination into the blood plasma. In particular, it has been demonstrated that HIV-1 induces cell-to-cell fusion with syncytia formation in some AIDS patients. The syncytia conglomerate consists of both infected CD4+ cells and HIV-1 virions, which serve as an HIV-1 disseminating unit by the mechanism of virological synapsemediated cell adhesion and viral endocytosis, as discussed in $[33,34,35]$. These authors concurred that the cell-to-cell-HIV-1 syncytia depicted by $\left(\beta_{2} x_{2} x_{3}\right)$ is much more efficient mechanism of HIV-1 infectivity as compared to the free virion mode of HIV-1 infectivity represented by $\left(\beta_{3} x_{3}\right)$.

\subsubsection{The CD8+ T cells dynamics}

$$
\dot{x}_{4}=S_{4}+a_{4} x_{1} x_{4} e^{-b_{4} x_{1}}-K_{2} x_{2} x_{4}-k_{4} x_{4}-e_{40}
$$

The instantaneous number of HIV-1 specific CD8+ T cells is equal to the rate of supply the thymus via hematopoietic progenitor cells; plus activation/proliferative recruitment of antigen activated and interleukin-2 stimulated HIV-1 specific CD8+ T cells $\left(a_{4} x_{1} x_{4} e^{-b_{4} x_{1}}\right)$; less the number of CD8 $+\mathrm{T}$ cells lost during cytolysis of HIV-1 infected CD4+ T cells $\left(K_{2} x_{2} x_{4}\right)$; less the number of HIV-1 specific CD8 + T cell lost by enzymatic degradation( $\left.k_{4} x_{4}\right)$; less the number of HIV-1 specific CD8+ lost by apoptosis/exfoliative cytolytic death $\left({ }^{e_{40}}\right)$.

\subsection{The Cauchy Problem for Dynamics of HIV-1 during the Acute and Chronic Phases}

In this section, the initial value problem (Cauchy problem) for HIV-1 dynamics during the acute and chronic phases will be mathematically analyzed and discussed with regard to well posedness, dissipativity of solutions, and invariance of non-negativity.

From the previous section, the mathematical model for HIV-1 dynamics during the acute and chronic phases can be described in terms of the following deterministic, non-linear and coupled ordinary differential equations. It is assumed that within certain biological limits the environment of the interactions between the uninfected CD4+ T cells, HIV-1 infected CD4+ T cells, HIV-1 virions in the blood plasma, and HIV-1 specific CD8+ T cells is homogeneous, isotropic and hence space independent. Thus ordinary differential equations can be used in the modeling. In the future, mathematical models using partial differential equations, stochastic differential equations, and delay differential equations will be presented. Thus the Cauchy problem is described by the following system of equations:

$$
\left\{\begin{array}{l}
\dot{x}_{1}=S_{1}+a_{1} x_{1}^{2} e^{-b_{1} x_{1}}-\alpha_{1} x_{1} x_{3}-q_{1} x_{1} x_{2}-k_{1} x_{1}-e_{10} \\
\dot{x}_{2}=S_{2}+a_{2} x_{1} x_{2} e^{-b_{2} x_{1}}+\alpha_{2} x_{1} x_{3}-q_{2} x_{1} x_{2}-k_{2} x_{2}-\beta_{1} x_{3}-K_{1} x_{2} x_{4}-e_{20} \\
\dot{x}_{3}=S_{3}+\beta_{2} x_{2} x_{3}+\beta_{3} x_{3}-\alpha_{3} x_{1} x_{3}-k_{3} x_{3}-e_{30} \\
\dot{x}_{4}=S_{4}+a_{4} x_{1} x_{4} e^{-b_{4} x_{1}}-K_{2} x_{2} x_{4}-k_{4} x_{4}-e_{40} \\
x_{i}\left(t_{0}\right)=x_{i 0} \text { for } i=\{1,2,3,4\}
\end{array}\right.
$$


Let $t_{0}$ be the time of the initial HIV-1 infection; and define $t_{L}, t_{P}$, repectively, as the time at which the latency phase begins and the time at which the post latency phase of HIV-1 dynamics commences in a patient. In particular, the phases $\left[t_{0}, t_{L}\right],\left[t_{L}, t_{P}\right]$ depict respectively the acute phase and the chronic phase of primary HIV-1 induced AIDS.

\subsection{Dissipativity and Boundedness of Solutions}

In this subsection, the dissipativity of the model equations will be discussed.

Definition: Consider the autonomous system of ordinary differential equations:

$$
\begin{aligned}
& \dot{x}=F(x) \quad x\left(t_{0}\right)=x_{0} \\
& \text { where } \quad x_{0}, x \in \mathfrak{R}^{n} \text { and } F \in C\left(\mathfrak{R}_{+}^{n}, \mathfrak{R}^{n}\right) \\
& \mathfrak{R}_{+}^{n}=\left\{x_{i} \in \mathfrak{R}^{n} \mid x_{i} \geq 0, i=1,2, \ldots, n\right\}
\end{aligned}
$$

Then the system (3.6) is dissipative if

$$
\lim _{t \rightarrow \infty} \operatorname{Sup}_{i}(t)<M_{i} \quad \text { where } M_{i} \in \mathfrak{R}_{+} \text {is bounded }
$$

In particular, the flow trajectories of the system are asymptotically uniformly bounded. For dissipative systems, the existence of an interior equilibrium is a consequence of uniform persistence, as discussed in [36-38]. Physiologically, the flow or output of a biological system is dissipative if it is bounded such that the associated flow or output cannot exceed a certain threshold or maximum value. Thus the physiological flow is homeostatically controlled by processes such as cell degradation, exfoliation, apoptosis, loss of clonogenicity and enzymatic/hormonal modulation. This guarantees that the solutions to the system of differential equations of the model are ultimately bounded and exhibit invariance of non-negativity.

The invariance of non-negativity, ultimate boundedness of solutions and dissipativity of the model equations will be shown as follows:

Let

$$
\begin{aligned}
& C_{j}=\operatorname{Sup}_{t \in\left[t_{0}, t_{P}\right]}\left\lfloor a_{j} x_{1} x_{j} e^{-b_{j} x_{1}}\right\rfloor \quad \text { for } j=\{1,2,4\} \\
& C_{3}=\operatorname{Sup}_{t \in\left[t_{0}, t_{P}\right]}\left[\beta_{2} x_{2} x_{3}+\beta_{3} x_{3}\right]
\end{aligned}
$$

Where $t_{L}$ is the time at which the latency phase begins. Similarly, $t_{P}$ is the time at which the post latency phase of HIV-1 dynamics commences in a patient and the time beyond which full-blown AIDS occurs.

Differential inequalities are constructed in an attempt to obtain upper bounds on the values of $x_{i}, i$ $=\{1,2,3,4\}$, based on some critical physiological interactions that affect their dynamics. The processes chosen in this model include the supply rates $S_{i}$, the IL-2 activation rates $g\left(x_{1}, x_{j}\right)$, clonogenic biodegradation rates $\left(k_{i} x_{i}\right)$ and apoptotic degradation rates $\left(e_{i 0}\right)$.

The system of differential equations (3.5) reduce to the following differential inequalities, 


$$
\begin{aligned}
& \text { for }^{t \in\left[t_{0}, t_{p}\right]} \text { : } \\
& \qquad \begin{array}{l}
\dot{x}_{1} \leq S_{1}+C_{1}-k_{1} x_{1}-e_{10} \\
\dot{x}_{2} \leq S_{2}+C_{2}-k_{2} x_{2}-e_{20} \\
\dot{x}_{3} \leq S_{3}+C_{3}-k_{3} x_{3}-e_{30} \\
\dot{x}_{4} \leq S_{4}+C_{4}-k_{4} x_{4}-e_{40}
\end{array}
\end{aligned}
$$

Using the Kamke comparison technique (see [39]), the differential inequalities lead to the following theorem.

\section{Theorem 3.1}

Let

$$
\begin{aligned}
& m_{i}=\underset{t \in\left[t_{0}, t_{P}\right]}{\operatorname{Max}}\left\{x_{i L}, \frac{S_{i}+C_{i}-e_{i 0}}{k_{i}}\right\} \\
& \text { for } \quad i=\{1,2,3,4\}
\end{aligned}
$$

Where

$$
\left\{\begin{array}{l}
x_{1}\left(t_{0}\right)=x_{10} \\
x_{2}\left(t_{0}\right)=x_{20} \\
x_{3}\left(t_{0}\right)=x_{30} \\
x_{4}\left(t_{0}\right)=x_{40}
\end{array}\right.
$$

and

$$
S_{i}+C_{i}-e_{i 0}>0
$$

Consider the set

$$
A=\left\{\left(x_{1}, x_{2}, x_{3}, x_{4}\right) \in \mathfrak{R}_{+}^{4} \mid 0 \leq x_{i}<m_{i}\right\}
$$

Then all solutions of the initial value problem (3.5) that originate in int $\Re_{+}{ }^{4}$ will eventually enter the set of $A$, such that the solution will be non-negative, ultimately bounded and remain in $A$ for all $t \in \mathfrak{R}_{+}$.

\section{$\underline{\text { Proof }}$}

The differential inequalities (3.8) can be used to obtain the following expressions:

$$
x_{i} \leq \frac{S_{i}+C_{i}-e_{i 0}}{k_{i}}+\sigma_{i 0} e^{-k_{i} t}
$$

where $\sigma_{i 0} \in \mathfrak{R}^{+}$and $i=\{1,2,3,4\}$

Hence, for $i=\{1,2,3,4\}$,

$\lim \operatorname{Sup} x_{i}(t) \leq \frac{S_{i}+C_{i}-e_{i 0}}{k_{i}}$

and 


$$
x_{i}(t) \in \operatorname{Sup}_{A}\left\{x_{i 0}, \frac{S_{i}+C_{i}-e_{i 0}}{k_{i}}\right\}
$$

Thus the flow associated with the system (3.5) is dissipative and non-negatively invariant if $S_{i}+C_{i}$ $-e_{i 0}>0$. In particular, the flow associated with the model equations (3.5) will eventually enter the set $A$ and remains trapped in $A$ for $t \in \Re^{+}$, if $x_{i 0} \in \operatorname{int} \Re_{+}{ }^{4}$.

\subsection{Criteria for Persistence of HIV-1 Virions in the Chronic Phase}

In this section, the criteria for the persistence of HIV-1 virions during the chronic phase will be derived. The definition of persistence and uniform persistence used in this section is similar to those elucidated in [36-38].

The differential equation for the HIV-1 patho- physiodynamics during the clinical chronic phase is:

$$
\dot{x}_{3}(t)=S_{3}+\beta_{2} x_{3}-\alpha_{3} x_{1} x_{3}-k_{3} x_{3}-e_{30}
$$

where $S_{3}$ is the reflux and repopulation rate of the plasma HIV-1 virions from the lymphoid tissue, microgial cells, reticules-endothelial cells, monocytes/macrophages and other sanctuaries. $e_{30}$ is a constant degradation rate of HIV-1 virions. $\beta_{2}$ is the "budding" rate constant of HIV-1 virions.

Let

$$
\bar{L}_{1}=\inf _{t \in\left[t_{L}, t_{P}\right]} x_{1}(t)
$$

and

$$
\begin{gathered}
S_{3}-e_{30} \geq 0 \\
\dot{x}_{3}(t) \geq S_{3}+\beta_{2} x_{3}-\alpha_{3} \overline{L_{1}} x_{3}-k_{3} x_{3}-e_{30}
\end{gathered}
$$

By solving (3.13) using Kamke's comparison technique, as discussed in [39, 40], the following inequality is obtained:

$$
x_{3}(t) \geq \frac{S_{3}-e_{30}}{k_{3}+\alpha_{3} \bar{L}_{1}-\beta_{2}}+k e^{-\left(k_{3}+\alpha_{3} \bar{L}_{1}-\beta_{2}\right) t}
$$

where $k$ is a positive constant.

In particular, the following theorems arise immediately:

\section{Theorem 3.2}

Suppose

(i) $S_{3}-e_{30}>0$

(ii) $k_{3}+\alpha_{3} L_{1}-\beta_{2}>0$ 
Then

$$
\liminf x_{3}(t) \geq \frac{S_{3}-e_{30}}{k_{3}+\alpha_{3} \bar{L}_{1}-\beta_{2}}>\mathrm{H}>0
$$

Where $\mathrm{H}$ is a bounded positive number of subclinical value. As a consequence, the number of HIV-1 virions in the blood plasma of the AIDS patient during the chronic phase will exhibit persistence. The patient will not develop full-blown AIDS if the value of $\mathrm{H}$ is such that the patient does not experience immune system paralysis.

\section{Theorem 3.3}

Suppose

(i) $S_{3}-e_{30}>0$

(ii) $k_{3}+\alpha_{3} L_{1}-\beta_{2}>0$

(iii) $0<\frac{S_{3}-e_{30}}{k_{3}+\alpha_{3} L_{1}-\beta_{2}}<\varepsilon$

where $\varepsilon$ is a small positive number.

Then the blood plasma HIV-1 viral titre is negligibly subclinical and the AIDS patient has insignificant HIV-1 RNA copies in the blood plasma during the chronic phase.

\section{Theorem 3.4}

Suppose

$$
\begin{aligned}
& \text { (i) } k_{3}+\alpha_{3} L_{1}-\beta_{2}<0 \\
& \text { (ii) } S_{3}-e_{30}>0
\end{aligned}
$$

Then the number of HIV-1 virions in the blood plasma increases exponentially. The HIV-1 positive patient will develop full-blown AIDS. Consequently, the patient will ultimately loose immuno-competency and eventually die as a result of opportunistic infections.

\section{Analyses of the Physiological Outcomes}

The clinically significant equilibrium patho-physiological outcomes of HIV-1 dynamics during the acute and chronic phases will be analyzed in this section using the principles of linearized stability. The outcomes are called equilibrium points or rest points of the model equations. The analyses will involve five clinically interesting equilibrium outcomes labeled $\left\{E_{i}: i=1,2,3,4,5\right\}$. 


\subsection{Criteria for Existence of Physiological Outcomes}

(i) $E_{1}=[0,0,0,0]:$ this represents the case in which uninfected $\mathrm{CD}^{+} \mathrm{T}$ cells, infected $\mathrm{CD} 4^{+}$ $\mathrm{T}$ cells, HIV-1 virions in blood plasma, and HIV-1 specific CD8+ T cells are all destroyed. This leads to the immune system paralysis in which the patient dies of opportunistic bacteria or viral infections. This case is clinically feasible if $S_{i}-e_{i 0}=0$.

(ii) $E_{2}=\left[\hat{x}_{1}, 0,0, \hat{x}_{4}\right]$ : this represents the case in which infected CD4 ${ }^{+} \mathrm{T}$ cells and HIV-1 virions in blood plasma are all destroyed. Clinical doctors working with HIV-1 infected patients would like to achieve this outcome. This equilibrium point is clinically possible under the following necessary conditions:

$$
\left\{\begin{array}{l}
S_{1}+a_{1} \hat{x}_{1}^{2} e^{-b_{1} \hat{x}_{2}}-k_{1} \hat{x}_{1}-e_{10}=0 \\
S_{2}-e_{20}=0 \\
S_{3}-e_{30}=0 \\
S_{4}+a_{4} \hat{x}_{1} \hat{x}_{4} e^{-b_{4} \hat{x}_{1}}-k_{4} \hat{x}_{4}-e_{40}=0
\end{array}\right.
$$

(iii) $E_{3}=\left[0, \bar{x}_{2}, \bar{x}_{3}, 0\right]$ : this depicts a clinically worst case situation in which both uninfected $\mathrm{CD} 4^{+} \mathrm{T}$ cells and HIV-1 specific $\mathrm{CD}^{+} \mathrm{T}$ cells are destroyed. This equilibrium point is clinically possible under the following necessary conditions:

$$
\left\{\begin{array}{l}
S_{1}-e_{10}=0 \\
S_{2}-\beta_{1} \bar{x}_{3}-k_{2} \bar{x}_{2}-e_{20}=0 \\
S_{3}-\beta_{2} \bar{x}_{3}-k_{3} \bar{x}_{3}-e_{30}=0 \\
S_{4}-e_{40}=0
\end{array}\right.
$$

(iv) $E_{4}=\left[\widetilde{x}_{1}, 0,0,0\right]$ : this is the most clinically desirable equilibrium point in which infected CD4+ T cells, plasma HIV-1 virions, and HIV-1 specific cytotoxic CD8+ T cells are all annihilated. The necessary conditions for the existence of this equilibrium point are:

$$
\left\{\begin{array}{l}
S_{1}+a_{1} \tilde{x}_{1}^{2} e^{-b_{1} \widetilde{x}_{2}}-k_{1} \tilde{x}_{1}-e_{10}=0 \\
S_{2}-e_{20}=0 \\
S_{3}-e_{30}=0 \\
S_{4}-e_{40}=0
\end{array}\right.
$$

(v) $E_{5}=\left[\breve{x}_{1}, \breve{x}_{2}, \breve{x}_{3}, \breve{x}_{4}\right]$ : this case can only exist if the equation (3.0) exhibits persistence in which all the four factors co-exist. The details of showing persistence in nonlinear systems of differential equations have been discussed in [39].

There are other equilibrium points such as $E\left[x_{1}, x_{2}, 0,0\right], E\left[0,0, x_{3}, \mathrm{x}_{4}\right]$ and many planar or axial points. These are clinically uninteresting and are not considered in this paper, but will be analyzed in a future paper. 


\subsection{Linearized Stability Analysis of Physiological Outcomes}

The Hartman-Grobman theorem ([40]) can be used to investigate the local physiological stability of HIV-1 AIDS disease dynamics associated with the model equations, in the neighborhood of the physiological outcomes (equilibrium states). The mathematical model is nonlinear and as such it is difficult to obtain any meaningful quantitative criteria about the model. Fortunately, the HartmanGrobman theorem guarantees that the information contained in the linearized system and the information contained the nonlinear system are equivalent in the neighborhood of the rest points. The Jacobian matrix of linearization near any physiological outcome is denoted symbolically by

$$
\begin{aligned}
J\left[E_{k}\right] & :=\left\{m_{i j}\right\} \in M_{4 \times 4}(\Re) \quad \text { where } k=1,2,3, \ldots \\
m_{11} & :=a_{1} x_{1}\left(2-b_{1} x_{1}\right) e^{-b_{1} x_{1}}-\alpha_{1} x_{3}-q_{1} x_{2}-k_{1} \\
m_{12} & :=-q_{1} x_{1} \\
m_{13} & :=-\alpha_{1} x_{1} \\
m_{14} & :=0 \\
m_{21} & :=a_{2} x_{2}\left(1-b_{2} x_{1}\right) e^{-b_{2} x_{1}}-q_{2} x_{2} \\
m_{22} & :=a_{2} x_{1} e^{-b_{2} x_{1}}-q_{2} x_{1}-k_{2}-K_{1} x_{4} \\
m_{23} & :=\alpha_{2} x_{1}-\beta_{1} \\
m_{24} & :=-K_{1} x_{2} \\
m_{31} & :=-\alpha_{3} x_{3} \\
m_{32} & :=\beta_{2} x_{3} \\
m_{33} & :=\beta_{2} x_{2}+\beta_{3}-\alpha_{3} x_{1}-k_{3} \\
m_{34} & :=0 \\
m_{41} & :=a_{4} x_{4}\left(1-b_{4} x_{1}\right) e^{-b_{4} x_{1}} \\
m_{42} & :=-K_{2} x_{4} \\
m_{43} & :=0 \\
m_{44} & :=a_{4} x_{1} e^{-b_{4} x_{1}}-K_{2} x_{2}-k_{4}
\end{aligned}
$$

\subsubsection{Criteria for annihilation of HIV-1 virions during the acute and chronic phases}

The Jacobian matrix of linearization in the neighborhood of E2 is given by the following matrix:

$$
\begin{aligned}
& J\left\{E_{2}\left[\hat{x}_{1}, 0,0, \hat{x}_{4}\right]\right\}= \\
& {\left[\begin{array}{cccc}
a_{1} \hat{x}_{1}\left(2-b_{1} \hat{x}_{1}\right) e^{-b_{1} \hat{x}_{1}}-k_{1} & -q_{1} \hat{x}_{1} & -\alpha_{1} \hat{x}_{1} & 0 \\
0 & a_{2} \hat{x}_{1} e^{-b_{2} \hat{x}_{1}}-q_{2} \hat{x}_{1}-k_{2}-K_{1} \hat{x}_{4} & \alpha_{2} \hat{x}_{1}-\beta_{1} & 0 \\
0 & 0 & \beta_{3}-\alpha_{3} \hat{x}_{1}-k_{3} & 0 \\
a_{4} \hat{x}_{4}\left(1-b_{4} \hat{x}_{1}\right) e^{-b_{4} \hat{x}_{1}} & -K_{2} \hat{x}_{4} & 0 & a_{4} \hat{x}_{1} e^{-b_{4} \hat{x}_{1}}-k_{4}
\end{array}\right]}
\end{aligned}
$$


The application of the principle of linearized stability and local stability theorems lead to the following:

\section{Theorem 4.1 Suppose}

$$
\begin{aligned}
& \text { (i) } \hat{x}_{1} \geq \frac{2}{b_{1}} \\
& \text { (ii) } a_{2} \hat{x}_{1} e^{-b_{2} \hat{x}_{1}}-K_{1} \hat{x}_{4}=0 \\
& \text { (iii) } \beta_{3} \leq k_{3} \\
& \text { (iv) } a_{4} \hat{x}_{1} e^{-b_{2} \hat{x}_{1}}-k_{4}<0
\end{aligned}
$$

Then the rest point $E_{2}\left[\hat{x}_{1}, 0,0, \hat{x}_{4}\right]$ is local attractor. In particular, the HIV-1 infected CD4+ T cells and the HIV-1 virions in the blood plasma of the AIDS patient are temporarily annihilated during the acute and chronic phases in the absence of the pharmacotherapy.

$\underline{\text { Proof }}$ The eigen-values of the Jacobian matrix (4.5) are associated with the equilibrium points $E_{2}$ are listed as follows:

$$
\left\{\begin{array}{l}
\lambda_{1}=a_{1} \hat{x}_{1}\left(2-b_{1} \hat{x}_{1}\right) e^{-b_{1} \hat{x}_{1}}-k_{1} \\
\lambda_{2}=a_{2} \hat{x}_{1} e^{-b_{2} \hat{x}_{1}}-q_{2} \hat{x}_{1}-k_{2}-K_{1} \hat{x}_{4} \\
\lambda_{3}=\beta_{3}-\alpha_{3} \hat{x}_{1}-k_{3} \\
\lambda_{4}=a_{4} \hat{x}_{1} e^{-b_{4} \hat{x}_{1}}-k_{4}
\end{array}\right.
$$

Using the principles of linearized stability as discussed in [20], it can be observed that the eigenvalues listed above are negative if the above conditions of (4.6a) hold.

Theorem 4.2 Suppose the following conditions hold:

$$
\hat{x}_{1}=\frac{2}{b_{1}}=\frac{\beta_{3}}{\alpha_{3}}
$$

$$
\hat{x}_{4}=\frac{a_{2} \hat{x}_{1} e^{-b_{2} \hat{x}_{1}}}{K_{1}}
$$

(iii) $a_{4} \hat{x}_{1} e^{-b_{4} \hat{x}_{1}}<k_{4}$

Then the local attractor $E_{2}$ can be written in the following form:

$$
E_{2}=\left[\frac{2}{b_{1}}, 0,0, \frac{2 a_{2} e^{-\frac{2 b_{2}}{b_{1}}}}{b_{1} K_{1}}\right]
$$

Proof Using (4.6b) and setting

$$
2-b_{1} \hat{x}_{1}=0 \text { and } \beta_{3}-\alpha_{3} \hat{x}_{1}=0
$$


For compatibility, (4.7)(i) is imposed. By implementing $a_{2} \hat{x}_{1} e^{-b_{2} \hat{x}_{1}}-K_{1} \hat{x}_{4}=0$ in (4.6b), (4.7)(ii) is obtained.

Observe that $\lambda_{4}$ in (4.6b) is negative if (4.7) (iii) holds. Hence, $E_{2}$ is a local attractor under the conditions specified in (4.7).

\section{The clinical implication of Theorem 4.2}

This result describes the transient annihilation of the HIV-1 virions and HIV-1 infected CD4+ T cells occurs during the acute and chronic phases if CD4+ T cells and CD8 $+\mathrm{T}$ cells number densities are given respectively by $\frac{2}{b_{1}}$ and $\frac{2 a_{2} e^{-\frac{2 b_{2}}{b_{1}}}}{b_{1} K_{1}}$. In particular, the autocrine activation rate function of $\mathrm{CD} 4+$ cells is given by

$$
\begin{gathered}
g\left(x_{1}, x_{1}\right)=a_{1} x_{1} x_{1} e^{-b_{1} x_{1}} \\
\approx \quad \frac{\frac{a_{1}}{b_{1}} x_{1} x_{1}}{\frac{1}{b_{1}}+x_{1}}
\end{gathered}
$$

The above equation is analogous to the Michaelis-Menten enzymatic-substrate activation reaction rate function with

$$
\frac{1}{b_{1}} \approx K_{m}
$$

Depicting the concentration of the CD4+ $\left(\mathrm{x}_{1}\right)$ cells when the rate of autocrine actvation is half of the maximum velocity and

$$
\frac{a_{1}}{b_{1}} \approx V_{\max }
$$

depicting the maximum velocity of autocrine activation reaction of the $\mathrm{CD} 4+\left(\mathrm{x}_{1}\right)$ cells.

Thus, Condition (i) of Theorem 4.2 specifies that the necessary condition for annihilation of the HIV-1 virions and the HIV-1 infected CD4+ cells is that twice the Michaelis-Menton constant for the $\mathrm{CD} 4+$ cell activation must be equal to the ratio of the HIV-1 production rate to the rate of infection of CD4+ cells by the HIV-1 virions.

When the conditions of Theorem 4.2 are violated, the HIV-1 positive person who is at the chronic stage of HIV infection will develop full-blown AIDS as described in [41]. On the other hand, if the conditions of Theorem 4.2 hold, the HIV-1 positive person will have stable chronic latency as described in [32]. 
Theorem 4.3 Suppose the conditions of Theorem 4.1 hold, and the following additional conditions hold:

(i)

$$
\begin{aligned}
& \text { (i) } \hat{x}_{1}>\frac{2}{b_{1}} \\
& \text { (ii) } k_{3}>\beta_{3} \\
& \text { (iii) } \frac{2}{b_{1}} \leq \hat{x}_{1} \leq-\frac{1}{b_{2}} \ln \left(\frac{q_{2}}{a_{2}}\right) \text { where } q_{2}<a_{2} \\
& \text { (iv) } a_{4} \hat{x}_{1} e^{-b_{4} \hat{x}_{1}}<k_{4}
\end{aligned}
$$

Then $E_{2}$ is a local attractor.

Proof The eigen-values of the Jacobian matrix of linearization as shown in (4.5) imply that the equilibrium $E_{2}$ is a local attractor if the conditions in (4.9) hold. In particular, the condition (iii) of (4.9) is derived as follows. From (4.6b), we have the condition $a_{2} e^{-b_{2} \hat{x}_{1}} \leq q_{2}$, which gives

$$
\hat{x}_{1} \leq-\frac{1}{b_{2}} \ln \left(\frac{q_{2}}{a_{2}}\right) \quad \text { where } \quad q_{2}<a_{2}
$$

Combining these results will obtain the condition (iii). The conditions ((i) - (iv) guarantee that the eigen-values are negative. Hence, $E_{2}$ is a locally asymptotically stable and a local attractor.

\section{Theorem 4.4 Suppose}

(i) $\frac{b_{1}}{b_{4}}=2$

(ii) $a_{2} \hat{x}_{1} e^{-b_{2} \hat{x}_{1}}-K_{1} \hat{x}_{4}=0$

(iii) $a_{2} \hat{x}_{1} e^{-b_{2} \hat{x}_{1}}-q_{2} \hat{x}_{1}-k_{2}-K_{1} \hat{x}_{4}<0$

(iv) $\beta_{3}-\alpha_{3} \hat{x}_{1}-k_{3}<0$

Then the rest point $E_{2}\left[\hat{x}_{1}, 0,0, \hat{x}_{4}\right]$ is local attractor. In particular, the HIV-1 infected CD4+ T cells and the HIV-1 virions in the blood plasma of the AIDS patient are temporarily annihilated during the acute and chronic phases in the absence of the pharmacotherapy.

Proof Using the Jacobian matrix (4.5), implementing (4.10)(i), and performing a Laplace expansion by the pivot $m_{11}=a_{1} x_{1}\left(2-b_{1} x_{1}\right) e^{-b_{1} x_{1}}-\alpha_{1} x_{3}-q_{1} x_{2}-k_{1}$, the eigen-values are listed as follows after simplification.

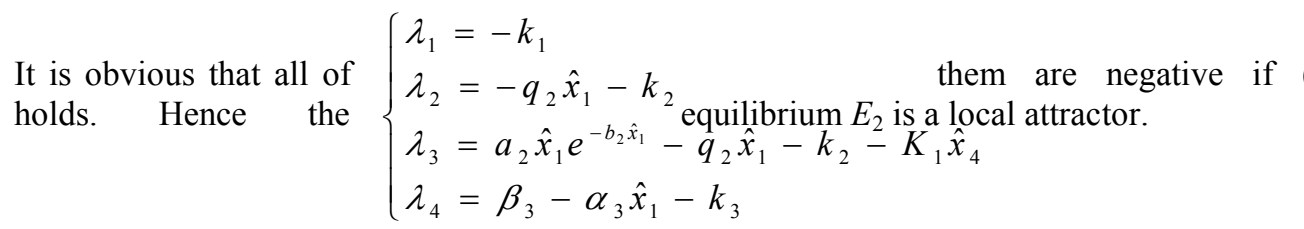




\subsubsection{The criteria for transient immune system paralysis during the acute and chronic phases of AIDS}

One of the rest points corresponding the immune system paralysis during primary AIDS infection is $E_{3}$. The Jacobian matrix of the linearization of the model equations in the neighborhood of $E_{3}$ is given as follows:

$$
\begin{aligned}
& J\left\{E_{3}\left[0, \bar{x}_{2}, \bar{x}_{3}, 0\right]\right\}= \\
& {\left[\begin{array}{cccc}
-\alpha_{1} \bar{x}_{3}-q_{1} \bar{x}_{2}-k_{1} & 0 & 0 & 0 \\
a_{2} \bar{x}_{2}-q_{2} \bar{x}_{2} & -k_{2} & -\beta_{1} & -K_{1} \bar{x}_{2} \\
\alpha_{3} \bar{x}_{3} & \beta_{2} \bar{x}_{3} & \beta_{2} \bar{x}_{2}+\beta_{3}-k_{3} & 0 \\
0 & 0 & 0 & -K_{2} \bar{x}_{2}-k_{4}
\end{array}\right]}
\end{aligned}
$$

The application of the principles of linearized stability gives the following result:

\section{Theorem 4.5}

Let
(i) $\beta_{2} \bar{x}_{2}+\beta_{3}-k_{3}-k_{2}<0$
(ii) $\beta_{1} \beta_{2} \bar{x}_{3}-k_{2}\left(\beta_{2} \bar{x}_{2}+\beta_{3}-k_{3}\right)>0$

Then the rest point $\mathrm{E}_{3}$ is local attractor.

Proof Using the Jacobian matrix of linearization (4.11), the eigen-spectrum of associated with $E_{3}$ is given by:

$$
\sigma\left(E_{3}\right)=\left\{\lambda \mid \operatorname{det}\left[\lambda \mathrm{I}_{4}-J\left\{E_{3}\right\}\right]=0\right\}
$$

where

$$
\begin{aligned}
& \lambda_{1}=-\alpha_{1} \bar{x}_{3}-q_{1} \bar{x}_{2}-k_{1} \\
& \lambda_{2}=-K_{2} \bar{x}_{2}-k_{4}
\end{aligned}
$$

and

$$
\lambda_{3}, \lambda_{4}
$$

solve the quadratic equation

$$
\lambda^{2}-\left(-k_{2}+\beta_{2} \bar{x}_{2}+\beta_{3}-k_{3}\right) \lambda+\beta_{1} \beta_{2} \bar{x}_{3}-k_{2}\left(\beta_{2} \bar{x}_{2}+\beta_{3}-k_{3}\right)=0
$$

Then the Routh-Hurwitz criterion as described in [40] can be used to show that $\lambda_{3}, \lambda_{4}$ are negative when conditions (4.12) (i) and (ii) hold. Under these conditions, $E_{3}$ is a local attractor The clinical implication of Theorem 4.5

The immune system of the AIDS patient is overwhelmed by transient immune system paralysis 
when the conditions (4.12) hold and the HIV-1 sero-positive will eventually develop full-blown AIDS.

The analysis of other rest points will be done in a future publication.

\subsection{Global Stability Analysis of Physiological Outcomes}

In this section, theoretical criteria will be presented for global stability of the clinically desirable physiological outcome $E_{2}\left[\hat{x}_{1}, 0,0, \hat{x}_{4}\right]$.

Consider space

$$
R_{+}^{x_{1} x_{4}}=\left[x_{1}, x_{4} \mid x_{1} \geq 0, x_{4} \geq 0\right]
$$

The model equations (3.5) correspondingly reduce to the following:

$$
\left\{\begin{array}{l}
\dot{x}_{1}=S_{1}+a_{1} x_{1}^{2} e^{-b_{1} x_{1}}-k_{1} x_{1}-e_{10} \\
\dot{x}_{4}=S_{4}+a_{4} x_{1} x_{4} e^{-b_{4} x_{1}}-k_{4} x_{4}-e_{40} \\
x_{i}\left(t_{0}\right)=x_{i 0} \quad \text { for } \quad i=\{1,4\}
\end{array}\right.
$$

Consider the Liapunov functional:

$$
\begin{aligned}
& V:=\sum \frac{1}{2} \hat{c}_{i}\left(x_{i}-\hat{x}_{i}\right)^{2} \\
& \quad \text { where } i=\{1,4\} \text { and } \hat{c}_{i} \in R_{+}=(0, \infty)
\end{aligned}
$$

The derivative of $\mathrm{V}$ along the solution curves of the model equations yields the result:

$$
\begin{aligned}
& \stackrel{*}{V}=\hat{c}_{1}\left(x_{1}-\hat{x}_{1}\right) \dot{x}_{1}+\hat{c}_{4}\left(x_{4}-\hat{x}_{4}\right) \dot{x}_{4} \\
& =\hat{c}_{1}\left(x_{1}-\hat{x}_{1}\right)\left(S_{1}+a_{1} x_{1}^{2} e^{-b_{1} x_{1}}-k_{1} x_{1}-e_{10}\right)+ \\
& \quad \hat{c}_{4}\left(x_{4}-\hat{x}_{4}\right)\left(S_{4}+a_{4} x_{1} x_{4} e^{-b_{4} \hat{x}_{1}}-k_{4} x_{4}-e_{40}\right)
\end{aligned}
$$

Define the following Lebesgue measurable, functions which are of bounded variation:

$$
\begin{gathered}
G\left(x_{1}\right)=a_{1} x_{1}^{2} e^{-b_{1} x_{1}} \\
F\left(x_{1}, x_{4}\right)=a_{4} x_{1} x_{4} e^{-b_{4} x_{1}} \\
* \quad \hat{c}_{1}\left(x_{1}-\hat{x}_{1}\right) \dot{x}_{1}+\hat{c}_{4}\left(x_{4}-\hat{x}_{4}\right) \dot{x}_{4} \\
=\hat{c}_{1}\left(x_{1}-\hat{x}_{1}\right)\left(-a_{1} \hat{x}_{1}^{2} e^{-b_{1} x_{1}}+k_{1} \hat{x}_{1}+a_{1} x_{1}^{2} e^{-b_{1} x_{1}}-k_{1} x_{1}\right)+ \\
\hat{c}_{4}\left(x_{4}-\hat{x}_{4}\right)\left(-a_{4} \hat{x}_{1} \hat{x}_{4} e^{-b_{4} \hat{x}_{1}}+k_{4} \hat{x}_{4}+a_{4} x_{1} x_{4} e^{-b_{4} x_{1}}-k_{4} x_{4}\right) \\
\left.=\hat{c}_{1}\left(x_{1}-\hat{x}_{1}\right)\left[G\left(x_{1}\right)-G\left(\hat{x}_{1}\right)\right]+\hat{c}_{1}\left(x_{1}-\hat{x}_{1}\right)\left(k_{1} \hat{x}_{1}-k_{1} x_{1}\right)\right]+ \\
\left.\hat{c}_{4}\left(x_{4}-\hat{x}_{4}\right)\left[F\left(x_{1}, x_{4}\right)-F\left(\hat{x}_{1}, \hat{x}_{4}\right)\right]+\hat{c}_{4}\left(x_{4}-\hat{x}_{4}\right)\left(k_{4} \hat{x}_{4}-k_{4} x_{4}\right)\right]
\end{gathered}
$$




$$
\begin{aligned}
\stackrel{*}{V}=- & \hat{c}_{1} k_{1}\left(x_{1}-\hat{x}_{1}\right)^{2}+\hat{c}_{1}\left(x_{1}-\hat{x}_{1}\right)\left[G\left(x_{1}\right)-G\left(\hat{x}_{1}\right)\right]+ \\
& \hat{c}_{4}\left(x_{4}-\hat{x}_{4}\right)\left[F\left(x_{1}, x_{4}\right)-F\left(\hat{x}_{1}, \hat{x}_{4}\right)\right]-\hat{c}_{4} k_{4}\left(x_{4}-\hat{x}_{4}\right)^{2}
\end{aligned}
$$

Let

and

$$
\begin{aligned}
& v_{1}=x_{1}-\hat{x}_{1} \\
& v_{2}=x_{4}-\hat{x}_{4}
\end{aligned}
$$

$$
X=\left[\begin{array}{l}
v_{1} \\
v_{2}
\end{array}\right] \in R_{+}^{2}
$$

and define define $A=\left\{a_{i j}\right\} \in M_{2 \times 2}(R)$ such that

$$
A=\left[\begin{array}{cc}
a_{11} & \frac{1}{2} a_{12} \\
\frac{1}{2} a_{21} & a_{22}
\end{array}\right]
$$

then

$$
\begin{aligned}
\stackrel{*}{V} & :=a_{11} v_{1}^{2}+\frac{1}{2} a_{12} v_{1} v_{2}+\frac{1}{2} a_{21} v_{2} v_{1}+a_{22} v_{2}^{2} \\
& =X^{T} A X
\end{aligned}
$$

Where $X^{T}$ denotes the transpose of $X$ and ${ }^{V}$ is negative definite if the eigen-values of $A$ have negative real parts.

In particular, the $\left[a_{i j}\right]_{2 \times 2}$ are defined as follows:

$$
\left\{\begin{array}{l}
a_{11}:=-\hat{c}_{1} k_{1}+\hat{c}_{1}\left(\frac{G\left(x_{1}\right)-G\left(\hat{x}_{1}\right)}{x_{1}-\hat{x}_{1}}\right) \\
a_{12}=a_{21}=0 \\
a_{22}:=-\hat{c}_{4} k_{4}+\hat{c}_{4}\left[\frac{F\left(x_{1}, x_{4}\right)-F\left(\hat{x}_{1}, \hat{x}_{4}\right)}{x_{4}-\hat{x}_{4}}\right]
\end{array}\right.
$$

As the flow dynamics approaches the steady state $E_{2}\left[x_{1}, 0,0, x_{4}\right]$, the following conditions hold:

$$
\begin{aligned}
& \left.a_{11} \rightarrow-\hat{c}_{1} k_{1}+G_{1}^{\prime}\left(\hat{x}_{1}\right)\right] \\
& a_{22} \rightarrow-\hat{c}_{4} k_{4}+\hat{c}_{4} F_{x_{4}}\left(\hat{x}_{1}, \hat{x}_{4}\right) \\
& G^{\prime}\left(\hat{x}_{1}\right)=a_{1} \hat{x}_{1} e^{-b_{1} \hat{x}_{1}}\left(2-b_{1} \hat{x}_{1}\right) \\
& F_{x_{4}}\left(\hat{x}_{4}\right)=a_{4} \hat{x}_{4} e^{-b_{4} \hat{x}_{1}}\left(1-b_{4} \hat{x}_{4}\right)
\end{aligned}
$$

But

Hence, the sufficient criteria for the global asymptotic stability of $E_{2}$ are specified in the following theorem. 
Theorem 4.6 Suppose the following conditions hold:

(i) Criterion (4.1)

(ii) $\hat{x}_{1} \geq \frac{2}{b_{1}}$

(iii) $\hat{x}_{4} \geq \frac{1}{b_{4}}$

Then the clinically desirable rest point $E_{2}$ is a global attractor.

\section{The clinical implication of Theorem 4.6}

Theorem 4.6 gives alternatively to two criterions which are otherwise different from Theorems 4.1-4.4, which characterizes the local stability of equilibrium point $E_{2}$ as a local attractor. Condition (ii) maintains that the $\mathrm{CD} 4+\mathrm{T}$ cells concentration must greater than or equal to twice of the Michaelis-Menten constant for the autocrine process CD4+ T cell activation. Condition (iii) requires that the cytotoxic $\mathrm{T}$ lymphocytes concentration must greater than or equal to the Michaelis-Menten constant of the $\mathrm{T}$ lymphocytes activation by the CD4+ $\mathrm{T}$ cells. The AIDS patient will experience permanent annihilation of the infected CD4+ T cells and HIV -1 virions in the blood plasma if the patient's patho-physio-dynamics conforms to the conditions specified in the theorem.

\section{Computer Simulation Results and Discussion}

In this section, investigative computer simulations are performed under specific parametric configurations. It must be stated emphatically that Theorems $4.1-4.4$ are applicable only to the equilibrium configurations $\left\{E_{i}: i=1,2,3,4, \ldots, n\right\}$. of the patho-physiodynamics of HIV-1 virus in the AIDS patient. These theorems are "if...then..." theorems and as such are fulfilled only when the AIDS dynamics attains the equilibrium configuration in the patient. In particular, there exist certain sufficient but not necessary criteria under which the AIDS patient can experience clinically favorable outcomes. On the other hand, under the specified conditions of Theorems 4.14.4 the predicted results are valid. The simulation results are presented in Sections 5.1 through 5.4. The time profile for the simulation is measured in years.

The problem of parameter estimation in mathematical modeling of physiological systems is a nontrivial one. There is a quasi-uniqueness of patho-physio-dynamics of disease in the patient and as such no two persons have identical physiological parametric configurations for a given disease. These phenomena have been discussed in the publication [21]. Several techniques concerning parameter estimation have been discussed by many authors in $[11,13,15-17,26,32,42]$.

Theorems 4.1-4.4, however, are based on equilibrium configurations of patho-physio-dynamics of AIDS. Thus, the techniques presented in the above references must be modified in order to obtain relevant estimates of the dynamical variables presented in this paper. In particular, in vitro and in vivo experiments as well as human biopsies from the peripheral blood of the AIDS patient are required in order to accurately determine most of the dynamical variables and constants of the model. Simulations based on equilibrium dynamics of AIDS using ACSL (Advanced Continuous Simulation Language) will be presented in a forthcoming paper. 


\subsection{Simulation results for hypothetical AIDS patient \#1}

The hypothetical patient \#1 possesses a non-equilibrium patho-physio-dynamics parametric configuration $P_{1}$ presented in Table 1 . The HIV-1 dynamics in this patient represents the classic profile for the acute and clinically chronic phases of AIDS. The simulation results for patient \#1 are exhibited in Fig. 1. It can observed that the HIV-1 infected CD4+ T cells and the blood plasmas HIV-1 virions are completely eradicated in this patient without the use of anti-AIDS pharmaco-therapeutic drug protocols. In addition, patient \#1 experiences immune system reconstitution as the uninfected CD4 $+\mathrm{T}$ cells repopulate and proliferate towards their pre-HIV -1 infection carrying capacities.

\subsection{Simulation results for hypothetical AIDS patient \#2}

For this simulation, the hypothetical AIDS patient \#2 is assigned the patho-physiological parameter configuration presented in Table 2. As in the previous simulation, the configuration P2 does not depict an equilibrium configuration. The simulation results are exhibited in Fig. 2. It can be observed that the patient does not have a clinically favorable prognosis. Because the disease has apparently progressed beyond the time point characterized as $t_{p}$, which is defined as the threshold time for full-blown AIDS. As presented in Fig. 2, the patient undergoes immune system paralysis in which the CD4+ T cells transiently destroyed. On the other hand, the cytotoxic activity of CD8 $+\mathrm{T}$ cells appears to be potent as observed in the eradication of the HIV -1 infected CD4+ T cells. Paradoxically the plasma HIV-1 viremia increases exponentially in the patient resulting in a more morbid AIDS outcome.

\subsection{Simulation results for hypothetical AIDS patient \#3}

The patho-physiological parametric configuration of patient \#3 is shown in Table 3 . It must be noted that the AIDS in this patient is in the acute phase and as such the simulation results span a time period lasting up to one year. The results of the simulation are in Figure 3. This is a nonequilibrium AIDS configuration simulation as it is evident by the simulation time profile. The simulation results show that at the end of the acute phase, the AIDS patient experiences annihilation of uninfected CD4+ T cells. In addition, the HIV-1 specific CD8+ T cells eradicate successfully the HIV-1 infected CD4+ T cells. Unfortunately the immune system paralysis, which occurs as a consequence of the low CD4+ $\mathrm{T}$ cell number density, eventually leads to an exponential increase of the blood plasma HIV-1 viremia. This simulation represents an unfavorable AIDS outcome during the acute phase.

\subsection{Simulation results for hypothetical AIDS patient \#4}

The simulation results for hypothetical patient $\# 4$ are exhibited in Fig. 4. These simulation results are based on the patho-physiological parametric configuration P4. In this patient the AIDS disease progresses from the acute phase into a 6 year clinically chronic phase before the development of full-blown AIDS.

\subsection{Simulation results for hypothetical AIDS patient \#5}

This scenario represents a relatively favorable progression of AIDS in hypothetical patient \#5. The data for the simulation results are given in Table 5 and the simulation results are displayed in Fig. 
5. The patho-physiological parametric configuration of this patient does not represent an equilibrium configuration and as such the condition of theorems 4.1-4.4 are not applicable. It can be observed from the simulation results that the patient would develop full-blown AIDS approximately after 10 years. On the other hand, the patient experiences relatively good immunecompetency from the beginning of the initial infection up to approximately 10 years before the onset of full-blown AIDS.

\subsection{Simulation results for hypothetical AIDS patient \#6}

The patho-physiological configuration of hypothetical patient \#6 is given in Table 6 . The simulation results depict an AIDS scenario which progresses from the acute phase through a relatively short chronic phase and heading towards the development of full-blown AIDS, as shown in Figure 6. It can be observed also that from the time period between 0 to 4 years the patient has sufficient immuno-competency as it is evident in the relatively higher dynamic number density of the CD4+ T cells and the HIV-1 specific CD8+ T cells as compared to the low dynamic number density of the HIV-1 infected CD4+ T cells and the blood plasma HIV-1 virions. Beyond the period of 6 years, then blood plasma HIV-1 virion and the HIV-1 infected CD4+ T cells number densities begin to rise as the patient heads towards the development of full-blown AIDS.
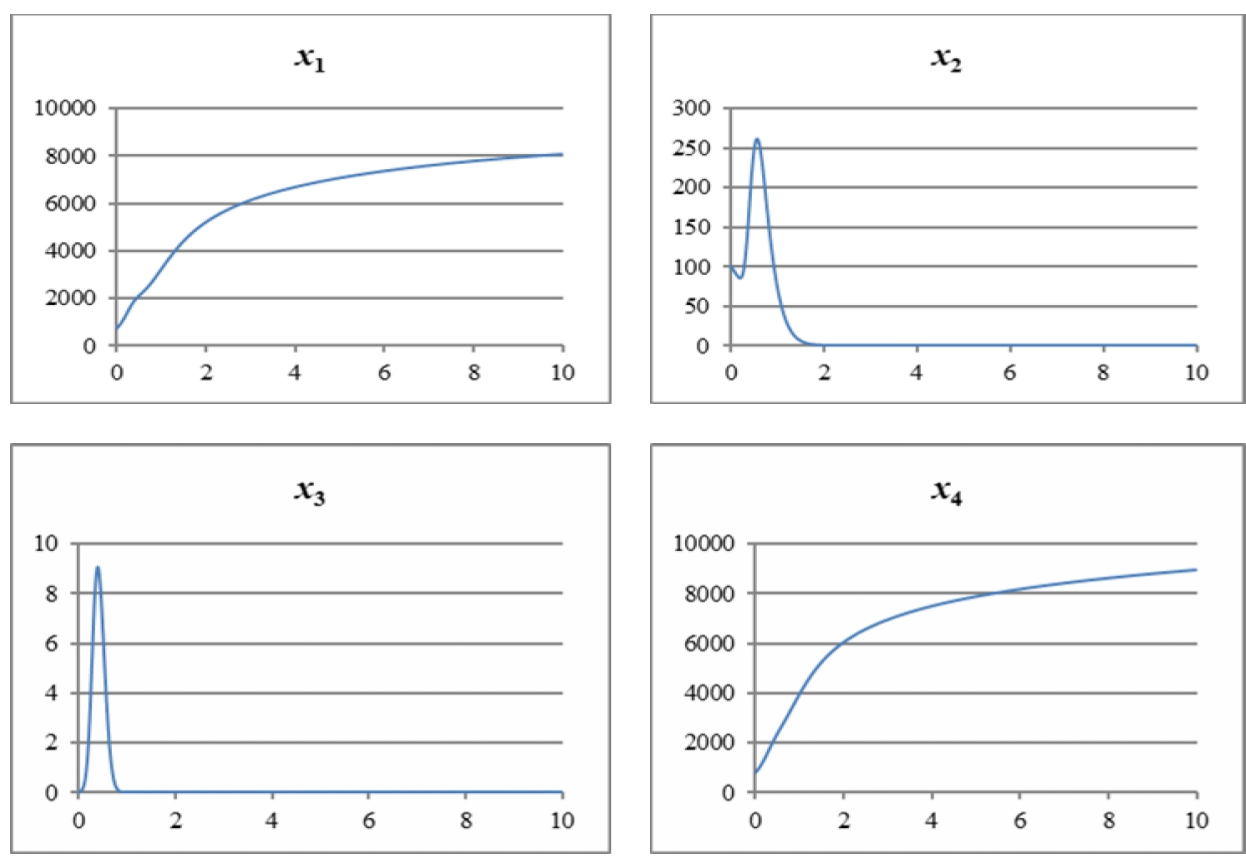

Fig. 1. Simulation results using parametric configuration $P_{1}$ 

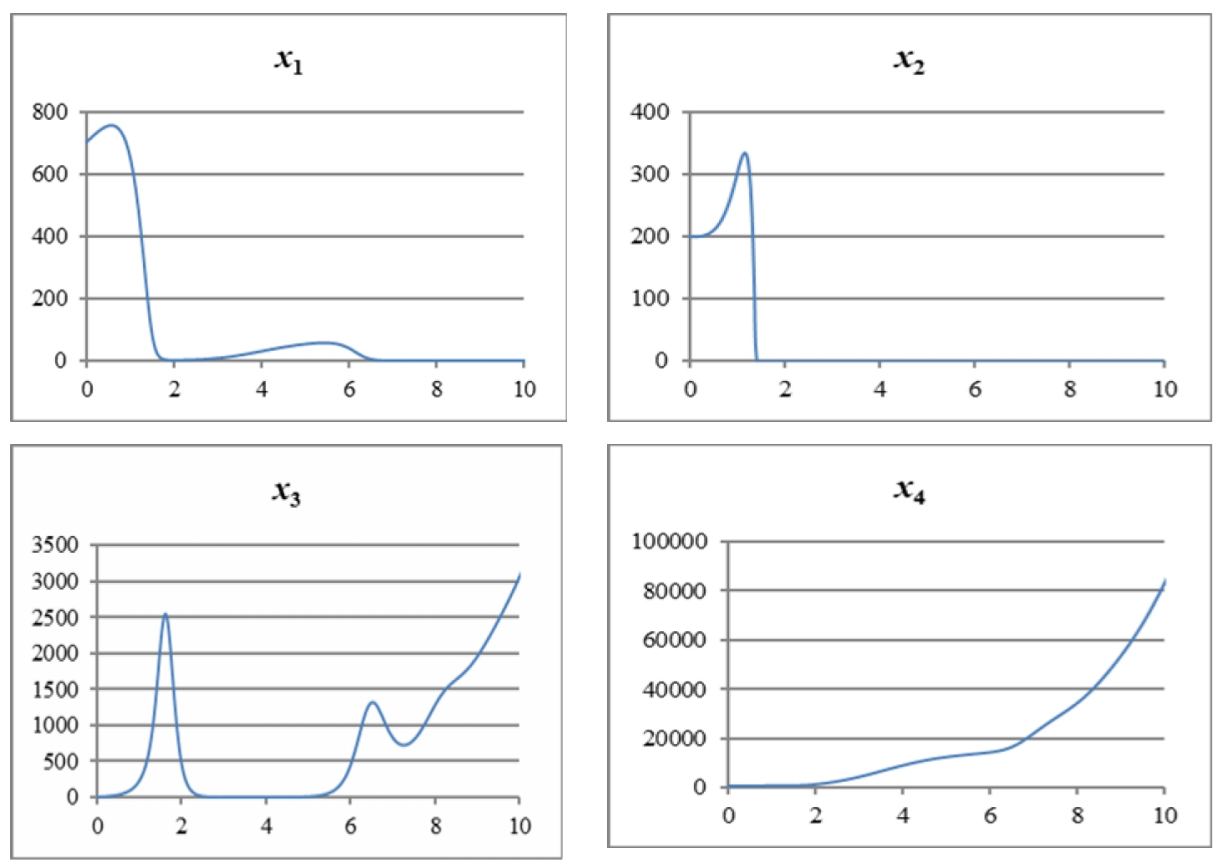

Fig. 2. Simulation results using parametric configuration $P_{2}$
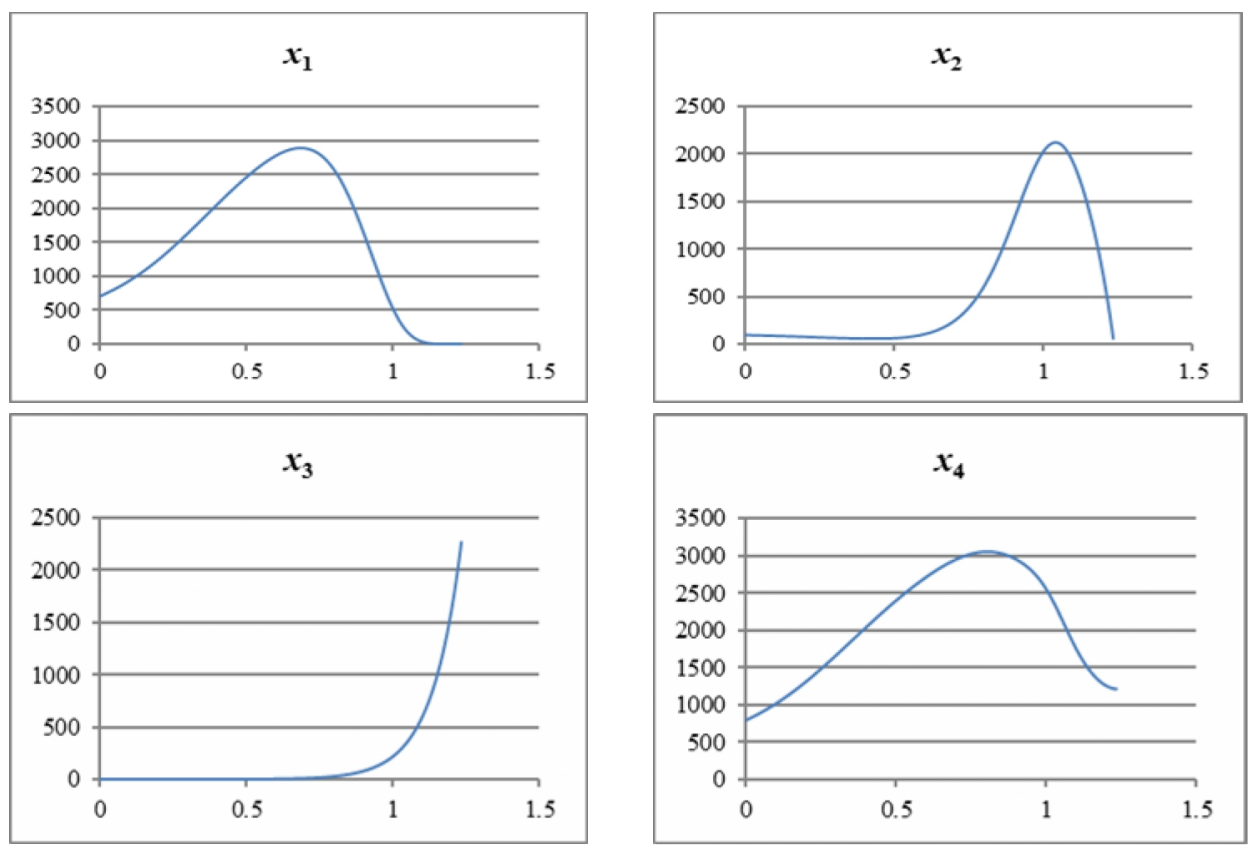

Fig. 3. Simulation results using parametric configuration $P_{3}$ 

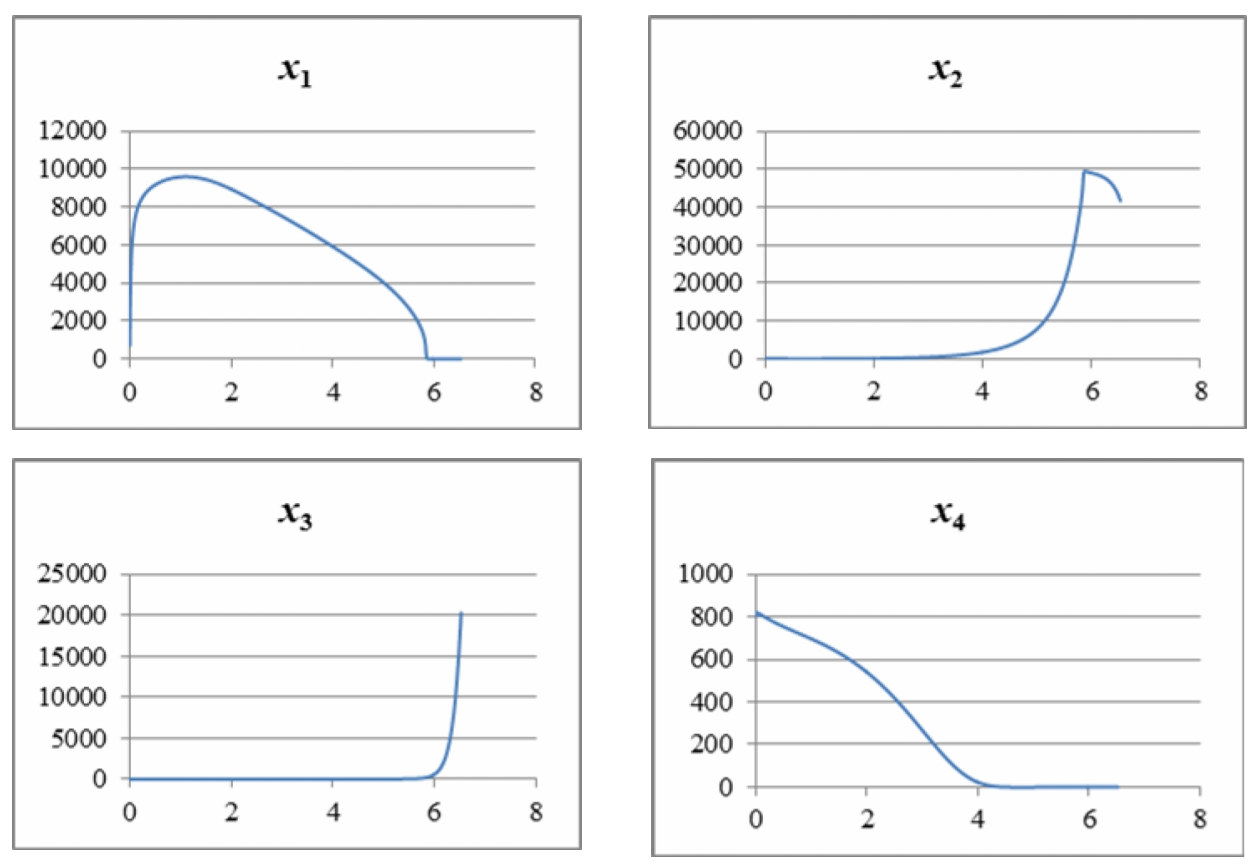

Fig. 4. Simulation results using parametric configuration $P_{4}$
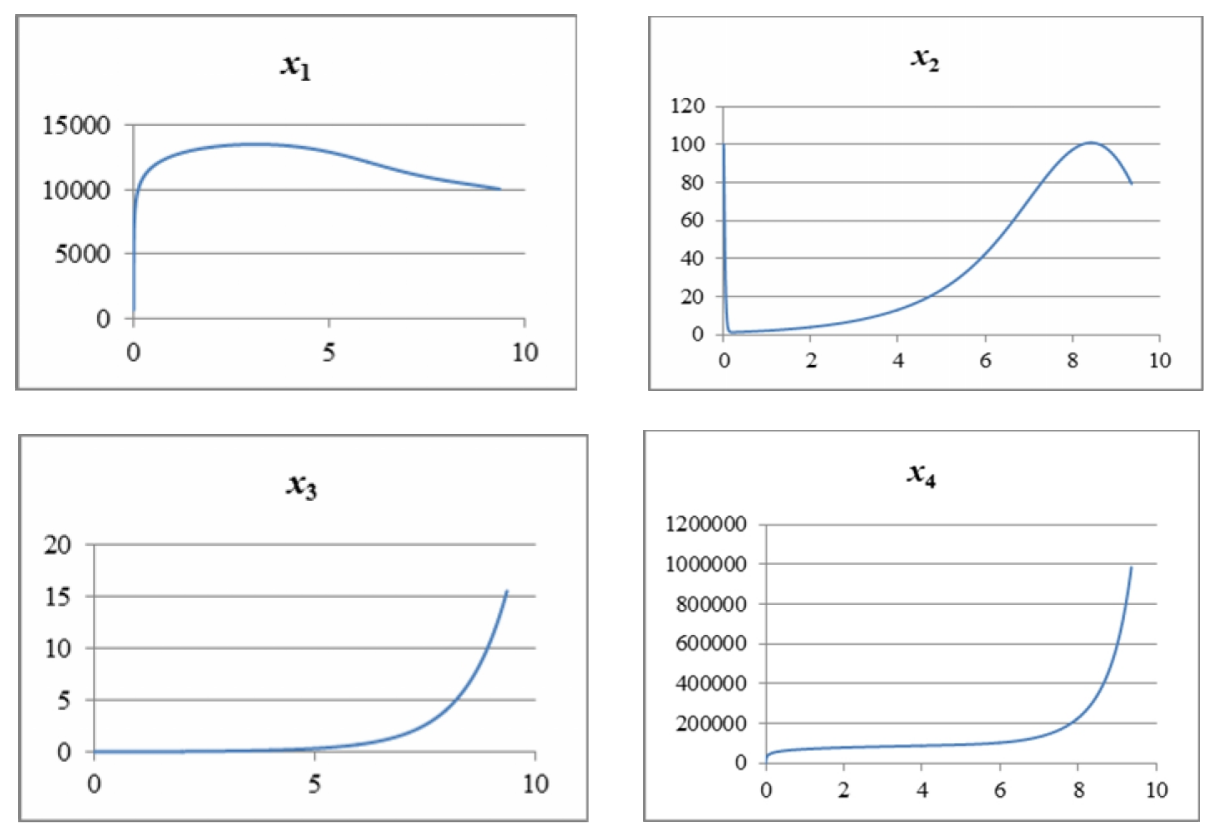

Fig. 5. Simulation results using parametric configuration $P_{5}$ 
British Journal of Mathematics \& Computer Science 4(11), 1450-1479, 2014

Table 1. Parametric Configuration $P_{1}$ (Absence of Syncytia $\beta_{2}=0$ )

\begin{tabular}{llll}
\hline$S_{1}=1.5 / \mathrm{day} / \mu l$ & $S_{2}=0.85 / \mathrm{day} / \mu l$ & $S_{3}=0.0 / \mathrm{day} / \mu l$ & $S_{4}=0.272 / \mathrm{day} / \mu l$ \\
$a_{1}=0.009 / \mathrm{day} / \mathrm{cell} / \mu l$ & $a_{2}=0.004 / \mathrm{day} / \mathrm{cell} / \mu l$ & $\beta_{2}=0 \mathrm{virons} / \mathrm{CD}^{+} / \mathrm{day} / \mu l$ & $a_{4}=0.0075 / \mathrm{day} / \mathrm{cell} / \mu l$ \\
$b_{1}=0.001 / \mathrm{cell} / \mu l$ & $b_{2}=0.004 / \mathrm{cell} / \mu l$ & $\beta_{3}=50 \mathrm{virons} / \mathrm{CD}^{+} / \mathrm{day}$ & $b_{4}=0.001 / \mathrm{cell} / \mu l$ \\
$\alpha_{1}=0.05 / \mathrm{day} / \mathrm{virion} / \mu l$ & $\alpha_{2}=0.1 / \mathrm{day} / \mathrm{virion} / \mu l$ & $\alpha_{3}=0.0027 / \mathrm{day} / \mathrm{virion} / \mu l$ & $K_{2}=0.0024 / \mathrm{day} / \mu l$ \\
$k_{1}=0.005 / \mathrm{day} / \mu l$ & $k_{2}=0.05 / \mathrm{day} / \mu l$ & $k_{3}=0.0001 / \mathrm{day}$ & $k_{4}=0.001 / \mathrm{day} / \mu l$ \\
$q_{1}=0.0045 / \mathrm{day} / \mu l / \mathrm{cell}$ & $q_{2}=0.0001 / \mathrm{day} / \mu l / \mathrm{cell}$ & $e_{30}=0.0001 / \mathrm{day}$ & $e_{40}=7.75 \mathrm{cells} / \mathrm{day} / \mu l$ \\
$\mathrm{e}_{10}=8.8 \mathrm{cells} / \mathrm{day} / \mu l$ & $\beta_{1}=50 \mathrm{virons} / \mathrm{CD} 4^{+} / \mathrm{day}$ & $x_{30}=0.01 \mathrm{cells} / \mu l$ & \\
$x_{10}=703 \mathrm{cells} / \mu l$ & $K_{1}=0.001 / \mathrm{day} / \mu l$ & & \\
& $e_{20}=0.005 \mathrm{cells} / \mathrm{day} / \mu l$ & & \\
& $x_{20}=100 \mathrm{cells} / \mu l$ & & \\
& & & \\
& & & \\
& & & \\
\end{tabular}

Table 2. Parametric Configuration $P_{2}$

\begin{tabular}{llll}
\hline$S_{1}=1.5 / \mathrm{day} / \mu l$ & $S_{2}=0.85 / \mathrm{day} / \mu l$ & $S_{3}=10.5 / \mathrm{day} / \mu l$ & $S_{4}=0.272 / \mathrm{day} / \mu l$ \\
$a_{1}=0.009 / \mathrm{day} / \mathrm{cell} / \mu l$ & $a_{2}=0.004 / \mathrm{day} / \mathrm{cell} / \mu l$ & $\beta_{2}=0.025 \mathrm{virons} / \mathrm{CD} 4^{+} / \mathrm{day} / \mu l$ & $a_{4}=0.0075 / \mathrm{day} / \mathrm{cell} / \mu l$ \\
$b_{1}=0.001 / \mathrm{cell} / \mu l$ & $b_{2}=0.004 / \mathrm{cell} / \mu l$ & $\beta_{3}=51 \mathrm{virons} / \mathrm{CD} 4^{+} / \mathrm{day}$ & $b_{4}=0.001 / \mathrm{cell} / \mu l$ \\
$\alpha_{1}=0.05 / \mathrm{day} / \mathrm{virion} / \mu l$ & $\alpha_{2}=0.1 / \mathrm{day} / \mathrm{virion} / \mu l$ & $\alpha_{3}=0.027 / \mathrm{day} / \mathrm{virion} / \mu l$ & $K_{2}=0.0024 / \mathrm{day} / \mu l$ \\
$k_{1}=0.005 / \mathrm{day} / \mu l$ & $k_{2}=0.05 / \mathrm{day} / \mu l$ & $k_{3}=0.0001 / \mathrm{day}$ & $k_{4}=0.08 / \mathrm{day} / \mu l$ \\
$q_{1}=0.0045 / \mathrm{day} / \mu l / \mathrm{cell}$ & $q_{2}=0.0001 / \mathrm{day} / \mu l / \mathrm{cell}$ & $e_{30}=0.0001 / \mathrm{day}$ & $e_{40}=10.75 \mathrm{cells} / \mathrm{day} / \mu$ \\
$\mathrm{e}_{10}=8.8 \mathrm{cells} / \mathrm{day} / \mu l$ & $\beta_{1}=51 \mathrm{virons} / \mathrm{CD} 4^{+} / \mathrm{day}$ & $x_{30}=5.5 \mathrm{cells} / \mu l$ & \\
$x_{10}=703 \mathrm{cells} / \mu l$ & $K_{1}=0.001 / \mathrm{day} / \mu l$ & & \\
& $e_{20}=0.005 \mathrm{cells} / \mathrm{day} / \mu l$ & & \\
& $x_{20}=200 \mathrm{cells} / \mu l$ & & \\
& &
\end{tabular}


British Journal of Mathematics \& Computer Science 4(11), 1450-1479, 2014

Table 3. Parametric Configuration $P_{3}$

\begin{tabular}{llll}
\hline$S_{1}=1.5 / \mathrm{day} / \mu l$ & $S_{2}=0.0 / \mathrm{day} / \mu l$ & $S_{3}=0.0 / \mathrm{day} / \mu l$ & $S_{4}=0.272 / \mathrm{day} / \mu l$ \\
$a_{1}=0.009 / \mathrm{day} / \mathrm{cell} / \mu l$ & $a_{2}=0.004 / \mathrm{day} / \mathrm{cell} / \mu l$ & $\beta_{2}=0.0 \mathrm{virons} / \mathrm{CD} 4^{+} / \mathrm{day} / \mu l$ & $a_{4}=0.0075 / \mathrm{day} / \mathrm{cell} / \mu l$ \\
$b_{1}=0.001 / \mathrm{cell} / \mu l$ & $b_{2}=0.004 / \mathrm{cell} / \mu l$ & $\beta_{3}=10 \mathrm{virons} / \mathrm{CD}^{+} / \mathrm{day}$ & $b_{4}=0.001 / \mathrm{cell} / \mu l$ \\
$\alpha_{1}=0.05 / \mathrm{day} / \mathrm{virion} / \mu l$ & $\alpha_{2}=0.1 / \mathrm{day} / \mathrm{virion} / \mu l$ & $\alpha_{3}=0 / \mathrm{day} / \mathrm{virion} / \mu l$ & $K_{2}=0.0024 / \mathrm{day} / \mu l$ \\
$k_{1}=0.005 / \mathrm{day} / \mu l$ & $k_{2}=0.05 / \mathrm{day} / \mu l$ & $k_{3}=0.0001 / \mathrm{day}$ & $k_{4}=0.001 / \mathrm{day} / \mu l$ \\
$q_{1}=0.0045 / \mathrm{day} / \mu l / \mathrm{cell}$ & $q_{2}=0.0001 / \mathrm{day} / \mu l / \mathrm{cell}$ & $e_{30}=0.0001 / \mathrm{day}$ & $e_{40}=7.75 \mathrm{cells} / \mathrm{day} / \mu l$ \\
$\mathrm{e}_{10}=8.8 \mathrm{cells} / \mathrm{day} / \mu l$ & $\beta_{1}=10 \mathrm{virons} / \mathrm{CD} 4^{+} / \mathrm{day}$ & $x_{30}=0.01 \mathrm{cells} / \mu l$ & $x_{40}=800 \mathrm{cells} / \mu l$ \\
$x_{10}=703 \mathrm{cells} / \mu l$ & $K_{1}=0.001 / \mathrm{day} / \mu l$ & & \\
& $e_{20}=0.005 \mathrm{cells} / \mathrm{day} / \mu l$ & & \\
& $x_{20}=100 \mathrm{cells} / \mu l$ & & \\
& & & \\
\hline
\end{tabular}

Table 4. Parametric Configuration $P_{4}$

\begin{tabular}{llll}
\hline$S_{1}=1.5 / \mathrm{day} / \mu l$ & $S_{2}=0.0 / \mathrm{day} / \mu l$ & $S_{3}=0.0 / \mathrm{day} / \mu l$ & $S_{4}=0.272 / \mathrm{day} / \mu l$ \\
$a_{1}=0 . .5 / \mathrm{day} / \mathrm{cell} / \mu l$ & $a_{2}=0.05 / \mathrm{day} / \mathrm{cell} / \mu l$ & $\beta_{2}=0.0001 \mathrm{virons} / \mathrm{CD}^{+} / \mathrm{day} / \mu l$ & $a_{4}=0.0075 / \mathrm{day} / \mathrm{cell} / \mu l$ \\
$b_{1}=0.001 / \mathrm{cell} / \mu l$ & $b_{2}=0.004 / \mathrm{cell} / \mu l$ & $\beta_{3}=2 \mathrm{virons} / \mathrm{CD}^{+} / \mathrm{day}$ & $b_{4}=0.001 / \mathrm{cell} / \mu l$ \\
$\alpha_{1}=0.05 / \mathrm{day} / \mathrm{virion} / \mu l$ & $\alpha_{2}=0.5 / \mathrm{day} / \mathrm{virion} / \mu l$ & $\alpha_{3}=0.0001 / \mathrm{day} / \mathrm{virion} / \mu l$ & $K_{2}=0.0024 / \mathrm{day} / \mu l$ \\
$k_{1}=0.005 / \mathrm{day} / \mu l$ & $k_{2}=0.05 / \mathrm{day} / \mu l$ & $k_{3}=0.0001 / \mathrm{day}$ & $k_{4}=0.08 / \mathrm{day} / \mu l$ \\
$q_{1}=0.0045 / \mathrm{day} / \mu l / \mathrm{cell}$ & $q_{2}=0.0001 / \mathrm{day} / \mu l / \mathrm{cell}$ & $e_{30}=0.0001 / \mathrm{day}$ & $e_{40}=7.75 \mathrm{cells} / \mathrm{day} / \mu l$ \\
$e_{10}=8.8 \mathrm{cells} / \mathrm{day} / \mu l$ & $\beta_{1}=2 \mathrm{virons} / \mathrm{CD} 4^{+} / \mathrm{day}$ & $x_{30}=0.01 \mathrm{cells} / \mu l$ & $x_{40}=800 \mathrm{cells} / \mu l$ \\
$x_{10}=703 \mathrm{cells} / \mu l$ & $K_{1}=0.001 / \mathrm{day} / \mu l$ & & \\
& $e_{20}=0.005 \mathrm{cells} / \mathrm{day} / \mu l$ & & \\
& $x_{20}=100 \mathrm{cells} / \mu l$ & & \\
& &
\end{tabular}


British Journal of Mathematics \& Computer Science 4(11), 1450-1479, 2014

Table 5. Parametric Configuration $P_{5}$

\begin{tabular}{llll}
\hline$S_{1}=1.5 / \mathrm{day} / \mu l$ & $S_{2}=0.0 / \mathrm{day} / \mu l$ & $S_{3}=0.0 / \mathrm{day} / \mu l$ & $S_{4}=0.272 / \mathrm{day} / \mu l$ \\
$a_{1}=2.5 / \mathrm{day} / \mathrm{cell} / \mu l$ & $a_{2}=0.05 / \mathrm{day} / \mathrm{cell} / \mu l$ & $\beta_{2}=0.0001 \mathrm{virons} / \mathrm{CD}^{+} / \mathrm{day} / \mu l$ & $a_{4}=4.0 / \mathrm{day} / \mathrm{cell} / \mu l$ \\
$b_{1}=0.001 / \mathrm{cell} / \mu l$ & $b_{2}=0.004 / \mathrm{cell} / \mu l$ & $\beta_{3}=2 \mathrm{virons} / \mathrm{CD}^{+} / \mathrm{day}$ & $b_{4}=0.001 / \mathrm{cell} / \mu l$ \\
$\alpha_{1}=0.05 /$ day $/ \mathrm{virion} / \mu l$ & $\alpha_{2}=0.5 / \mathrm{day} / \mathrm{virion} / \mu l$ & $\alpha_{3}=0.0001 / \mathrm{day} / \mathrm{virion} / \mu l$ & $K_{2}=0.0024 / \mathrm{day} / \mu l$ \\
$k_{1}=0.005 / \mathrm{day} / \mu l$ & $k_{2}=0.05 / \mathrm{day} / \mu l$ & $k_{3}=0.0001 / \mathrm{day}$ & $k_{4}=0.001 / \mathrm{day} / \mu l$ \\
$q_{1}=0.0045 / \mathrm{day} / \mu l / \mathrm{cell}$ & $q_{2}=0.0001 / \mathrm{day} / \mu l / \mathrm{cell}$ & $e_{30}=0.0001 / \mathrm{day}$ & $e_{40}=7.75 \mathrm{cells} / \mathrm{day} / \mu l$ \\
$\mathrm{e}_{10}=8.8 \mathrm{cells} / \mathrm{day} / \mu l$ & $\beta_{1}=2 \mathrm{virons} / \mathrm{CD} 4^{+} / \mathrm{day}$ & $x_{30}=0.01 \mathrm{cells} / \mu l$ & $x_{40}=800 \mathrm{cells} / \mu l$ \\
$x_{10}=703 \mathrm{cells} / \mu l$ & $K_{1}=0.001 / \mathrm{day} / \mu l$ & & \\
& $e_{20}=0.005 \mathrm{cells} / \mathrm{day} / \mu l$ & & \\
& $x_{20}=100 \mathrm{cells} / \mu l$ & & \\
& & & \\
\end{tabular}

Table 6. Parametric Configuration $P_{6}$

\begin{tabular}{llll}
\hline$S_{1}=1.5 /$ day $/ \mu l$ & $S_{2}=0.0 / \mathrm{day} / \mu l$ & $S_{3}=0.0 / \mathrm{day} / \mu l$ & $S_{4}=0.272 / \mathrm{day} / \mu l$ \\
$a_{1}=1.5 /$ day $/$ cell $/ \mu l$ & $a_{2}=0.05 / \mathrm{day} / \mathrm{cell} / \mu l$ & $\beta_{2}=0.0001$ virons $/ \mathrm{CD}^{+} / \mathrm{day} / \mu l$ & $a_{4}=3.0 / \mathrm{day} / \mathrm{cell} / \mu l$ \\
$b_{1}=0.001 / \mathrm{cell} / \mu l$ & $b_{2}=0.004 / \mathrm{cell} / \mu l$ & $\beta_{3}=2 \mathrm{virons} / \mathrm{CD}^{+} / \mathrm{day}$ & $b_{4}=0.001 / \mathrm{cell} / \mu l$ \\
$\alpha_{1}=0.05 / \mathrm{day} / \mathrm{virion} / \mu l$ & $\alpha_{2}=0.5 / \mathrm{day} / \mathrm{virion} / \mu l$ & $\alpha_{3}=0.0001 / \mathrm{day} / \mathrm{virion} / \mu l$ & $K_{2}=0.0024 / \mathrm{day} / \mu l$ \\
$k_{1}=0.005 / \mathrm{day} / \mu l$ & $k_{2}=0.05 / \mathrm{day} / \mu l$ & $k_{3}=0.0001 / \mathrm{day}$ & $k_{4}=0.001 / \mathrm{day} / \mu l$ \\
$q_{1}=0.0045 / \mathrm{day} / \mu l / \mathrm{cell}$ & $q_{2}=0.0001 / \mathrm{day} / \mu l / \mathrm{cell}$ & $e_{30}=0.0001 / \mathrm{day}$ & $e_{40}=7.75 \mathrm{cells} / \mathrm{day} / \mu l$ \\
$\mathrm{e}_{10}=8.8 \mathrm{cells} / \mathrm{day} / \mu l$ & $\beta_{1}=2 \mathrm{virons} / \mathrm{CD} 4^{+} / \mathrm{day}$ & $x_{30}=0.01 \mathrm{cells} / \mu l$ & $x_{40}=800 \mathrm{cells} / \mu l$ \\
$x_{10}=703 \mathrm{cells} / \mu l$ & $K_{1}=0.001 / \mathrm{day} / \mu l$ & & \\
& $e_{20}=0.005 \mathrm{cells} / \mathrm{day} / \mu l$ & & \\
& $x_{20}=100 \mathrm{cells} / \mu l$ & & \\
& &
\end{tabular}



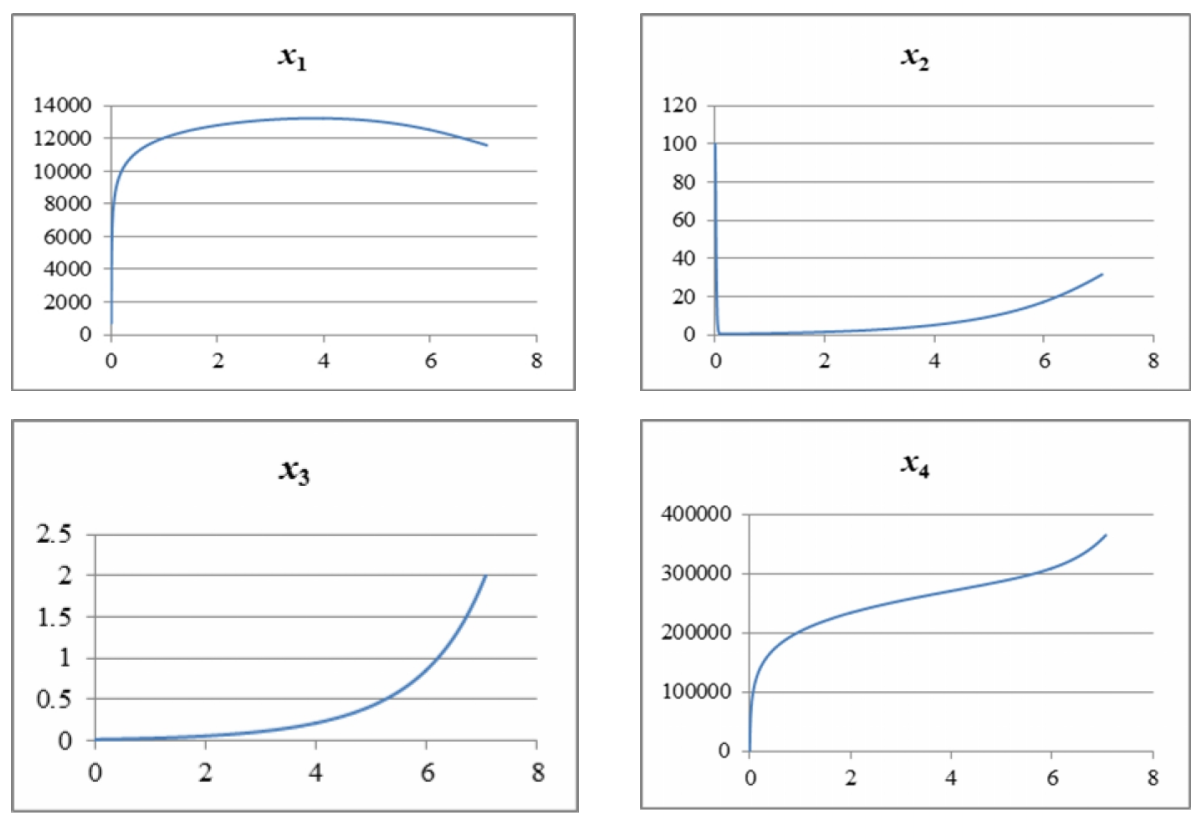

Fig. 6. Simulation results using parametric configuration $P_{6}$

\section{Summarizing Remarks}

In this paper, we have constructed a generalized and plausible mathematical model of HIV-1 dynamics during the acute and chronic phases. The special contribution of this model is the inclusion of explicit role of source terms $S_{1}, S_{2}, S_{3}, S_{4}$, which depict recruitment from the thymus gland and the HIV-1 viral reservoirs. Also, clinically relevant activation functions describing the action of IL-2 on the T cells are also included in the model equations. The activation functions are mathematical analogues of biological processes of autocrine and paracrine activations. It has been demonstrated that the activation function is comparable to the Michaelis-Menten kinetic function after the parameter re-calibration. The conditions for existence of the clinical outcomes are clearly exhibited in terms of biologically quantifiable and clinically measurable parameters. In particular, the simulation results depict the scenario of chronic asymptomatic HIV-1 infection during chronic latency phase in which the infected $\mathrm{CD}^{+} \mathrm{T}$ cells and the plasma, viremia are annihilated. The results elucidate and exhibit additional details of HIV-1 dynamics compared to the cited literature. The criteria under which HIV-1 sero-positive person will remain indefinitely in the chronic phase are stated and proved in Theorems 4.1-4.4 and 4.6. In addition, it has been shown in Theorem 4.5 that HIV-1 virions can under certain necessary and sufficient conditions can annihilate CD4+ T cells, leading to manifestation of full-blown AIDS. In a future publication, additional computer simulations will be presented elucidating Theorems 4.1-4.6.

\section{Competing interests}

Authors have declared that no competing interests exist. 


\section{References}

[1] Adle-Biassette H, et al. Neuronal apoptosis in HIV infection in adults, 12 May 2008. DOI: 10.1111/j.1365-2990.1995.tb01053.x.

[2] Kaul M, Lipton SA. Mechanisms of neuronal injury and death in HIV-1 associated dementia. Current HIV Research. 2006;4(3):307-18.

[3] Burton A. New mechanism for HIV infection of neurons discovered, The Lancet Neurology. 2003;2(2):71. DOI:10.1016/S1474-4422(03)00295-3.

[4] Pantaleo G, Fauci AS. HIV infection is active and progressive in lymphoid tissue during the clinically latent stage of disease. Nature. 1993;362:355.

[5] Pantaleo G, Graziosi C, Demarest JF. HIV infection is active and progressing in lymphoid tissue during the clinically latent stage of disease. Nature. 1993;362:355-358.

[6] Siliciano RF. Immunodeficiency in HIV-1 infection in: AIDS and Other Manifestations of HIV Infection, 3rd ed. Wormser G. (Ed.), Lippincott-Raven Publishers, Philadelphia. 1998:257-278.

[7] Wassef NM, Young J. Miller R. Viral reservoirs/transient infection in HIV/AIDS: Where are we now and where should we go? AIDS Research and Human Retroviruses. 2003;19(11):333-344.

[8] Walker CM, Moody DJ, Stites DP, Levy JA. CD8+ lymphocytes can control HIV infection In vitro by suppressing virus replication. Science. 1986;234:1563-1566.

[9] Suspène R, Meyerhans A. Quantification of Unintegrated HIV-1 DNA at the Single Cell Level In vivo. PLoS ONE. 2012;7(5):36246. DOI:10.1371/journal.pone.0036246.

[10] Essunger P, Perelson AS. Modeling HIV infection of CD 4+ T-cell subpopulations. J. thero. Biol. 1994;170(4):367-91.

[11] Perelson AS, Nelson P. Mathematical analysis of HIV-1 dynamics In vivo, SIAM Rev. 1999;41(1):3-44.

[12] Kirschner D, Webb GF. A model for treatment strategy in the chemotherapy of AIDS. Bull. Math. Biol. 1996;58:367-390.

[13] Wodarz D, Lloyd A. Dynamics of macrophage and T cell infection by HIV. J. theor. Biol. 1999;196:101-113.

[14] Wodarz D. Helper-dependent vs. helper-independent CTL responses in HIV infection: implications for drug therapy and resistance. J. theor. Biol. 2001;213:447-459.

[15] Wodarz D, Nowark M. Specific therapy regimes could lead to long-term immunological control of HIV. Pro. Natl. Acad. Sci. USA. 1999;96(25):14464-14469.

[16] Perelson AS, Neumann AU, Markwitz M. Viral dynamics In vivo: Virion clearance rate, infected cell life-span, viral generation time. Science. 1996;271:1582-1586. 
[17] Ciupe MS, Bivort BL, Bortz DM, Nelson PW. Estimating kinetic parameters from HIV primary infection data through the eyes of three different mathematical models, Mathematical Biosciences 200. 2006:1-27.

[18] Li MY, Shu H. Global dynamics of a mathematical model for HTLV-1 infection of CD4+ T cells with delayed CTL response, Nonlinear Analysis: Real World. 2011. Applications DOI: 10.1016/j.nonrwa. 2011.02.026

[19] Wang L, Li MY. Mathematical analysis of the global dynamics of a model for HIV infection of CD4+ T cells. Math Biosci. 2006;200:44-57.

[20] Tuckwell HC, Corfec EL. A stochastic model for early HIV-1 population dynamics. J. theor. Biol. 1998;195:451-463.

[21] Wu H, Ding A, De Gruttola V. Why are the decay rates in plasma HIV-1 different for different treatments and in different patient populations? AIDS. 1999;13(3):429-430.

[22] Reddy YS, Kashuba A. Importance of antiretroviral drug concentration in sanctuary sites and viral reservoirs. AIDS Research and Human Retroviruses. 2003;19(11):167-176.

[23] Rubbert A. Course of HIV RNA in CD4+ and CD8+ lymphocytes in HIV-infected patients undergoing HAART as determined by ultrasensitive fluorescence in Situ hybridization (UFISH). Proc. of the $9^{\text {th }}$ Conf. on Retroviruses and Opportunistic Infections; 2002.

[24] Souza, S, Crowe S. Reservoirs for HIV infection and their persistence in the face of undetectable viral load. AIDS Patient Care and STDs. 2001;15(10).

[25] Nowark MA, Bangham CRM. Population dynamics of immune responses to persistent viruses. Science 272. 1996:74-79.

[26] Chun TW, Fauci AS. Latent reservoirs of HIV: Obstacles to the eradication of virus. Proc. Natl. Acad Sci USA 96. 1999:10958.

[27] Graziosi C. Kinetics of human immunodeficiency virus type 1 (HIV-1) DNA and RNA synthesis during primary HIV-1 infection. Proc Natl Acad Sci. USA. 1993;90:6405.

[28] Clark SJ, Shaw GM. The acute retroviral syndrome and the patho-genesis of HIV-1 infection, Semin Immunology. 1993;5:149.

[29] Chun T, Engel D, Berrey M, Shea T, Corey L, Fauci A. Early establishment of a pool of latently infected, resting CD4+ T cells during primary HIV-1 infection, Proc. Natl. Acad. Sci. USA. 1998;95:8869-8873.

[30] Zauli G, La Placa M, Vignoli M, Re MC, Gibellini D, Furlini G, Milani D, Marchisio M, Mazzoni M, Capitani S. An autocrine loop of HIV type-1 Tat protein responsible for the improved survival/proliferation capacity of permanently Tat-transfected cells and required for optimal HIV-1 LTR transactivating activity, J Acquir Immune Defic Syndr Hum Retrovirol. 1995;10(3):306-16. 
[31] Ameisen JC, Estaquier J, Idziorek T, De Bels F. The relevance of apoptosis to AIDS pathogenesis, Trends Cell Biol. 1995;5(1):27-32.

[32] Chun TW, Finzi D, Margolick J. Fate of HIV-1 infected T-cells in vivo: Rates of transition to stable latency. Nat Med. 1996;334:1222-1330.

[33] Song B, Lou J, Wen Q. Modeling two different therapy strategies for drug T-20 on HIV-1 patients. Applied Math. Mech., -Engl. Ed. 2011;32(4):419-436.

[34] Sodroski J, Goh WC, Rosen C, Campbell K, Haseltine WA. Role of the HTLV-III/LAV envelope in syncytium formation and cytopathicity. Nature. 1986;322:470-474.

[35] Wolfgang H, McNerney GP, Chen P, Dale BM, Gordon RE, Chuang FYS, Li X, Asmuth DM, Huser T, Chen BK. Quantitative 3D video microscopy of HIV transfer across T-cell virological synapses. Science, 2009;323(5922):1743-1747.

[36] Gard TC. Uniform persistence in multispecies population models, Math. Biosci. 1987;85:93-104.

[37] Butler GJ, Freedman HI, Waltman PE. Uniformly persistent systems, Proc. Amer. Math. Soc. 1986;96:425-430.

[38] Butler GJ, Waltman, P. Persistence in the three-dimensional Lotka-Volterra systems, Mathl, comput. Modeling. 1988;10:13-16.

[39] Nani F, Freedman HI. A mathematical model of cancer treatment by immunotherapy. Mathematical Biosciences. 2000;163:159-199.

[40] Amann, H. Ordinary Differential Equations, An Introduction to Nonlinear Analysis, Walter de Gruyter and Co, Berlin. 1990;209.

[41] Daar ES. Transient high levels of viremia in patients with primary human immunodeficiency virus type I infection. New Engl. J. Med. 1991;324:961.

[42] Han C, Chaloner K, Perelson AS. Bayesian analysis of a population HIV dynamic model. Case Studies in Bayesian Statistics, Springer-Verlag: New York. 2002;6.

(C) 2014 Nani \& Jin; This is an Open Access article distributed under the terms of the Creative Commons Attribution License (http://creativecommons.org/licenses/by/3.0), which permits unrestricted use, distribution, and reproduction in any medium, provided the original work is properly cited.

Peer-review history:

The peer review history for this paper can be accessed here (Please copy paste the total link in your browser address bar)

www.sciencedomain.org/review-history.php?iid=477\&id=6\&aid=4131 